\title{
Carrier Lifetime Measurement by the Photoconductive Decay Method
}

U.S. ARTMENT OF JMMERCE National D...eau PC of 20 ds 753 .736 172 
The National Bureau of Standards ${ }^{1}$ was established by an act of Congress March 3, 1901. The Bureau's overall goal is to strengthen and advance the Nation's science and technology and facilitate their effective application for public benefit. To this end, the Bureau conducts research and provides: (1) a basis for the Nation's physical measurement system, (2) scientific and technological services for industry and government, (3) a technical basis for equity in trade, and (4) technical services to promote public safety. The Bureau consists of the Institute for Basic Standards, the Institute for Materials Research, the Institute for Applied Technology, the Center for Computer Sciences and Technology, and the Office for Information Programs.

THE INSTITUTE FOR BASIC STANDARDS provides the central basis within the United States of a complete and consistent system of physical measurement; coordinates that system with measurement systems of other nations; and furnishes essential services leading to accurate and uniform physical measurements throughout the Nation's scientific community, industry, and commerce. The Institute consists of a Center for Radiation Research, an Office of Measurement Services and the following divisions:

Applied Mathematics-Electricity-Heat-Mechanics-Optical Physics-Linac Radiation ${ }^{2}-$ Nuclear Radiation ${ }^{2}$ - Applied Radiation ${ }^{2}$-Quantum Electronics ${ }^{3}$ Electromagnetics ${ }^{3}$-Time and Frequency ${ }^{3}$ - Laboratory Astrophysics ${ }^{3}-$ Cryo- $^{-}$ genics ${ }^{3}$.

THE INSTITUTE FOR MATERIALS RESEARCH conducts materials research leading to improved methods of measurement, standards, and data on the properties of well-characterized materials needed by industry, commerce, educational institutions, and Government; provides advisory and research services to other Government agencies; and develops, produces, and distributes standard reference materials. The Institute consists of the Office of Standard Reference Materials and the following divisions:

Analytical Chemistry-Polymers-Metallurgy-Inorganic Materials-Reactor Radiation-Physical Chemistry.

THE INSTITUTE FOR APPLIED TECHNOLOGY provides technical services to promote the use of available technology and to facilitate technological innovation in industry and Government; cooperates with public and private organizations leading to the development of technological standards (including mandatory safety standards), codes and methods of test; and provides technical advice and services to Government agencies upon request. The Institute also monitors NBS engineering standards activities and provides liaison between NBS and national and international engineering standards bodies. The Institute consists of a Center for Building Technology and the following divisions and offices:

Engineering Standards Services-Weights and Measures-Invention and Innovation-Product Evaluation Technology-Electronic Technology-Technical Analysis-Measurement Engineering-Fire Technology-Housing Technology ${ }^{4}$ -Federal Building Technology ${ }^{4}$ - Building Standards and Codes Services ${ }^{4}$ Building Environment ${ }^{4}$-Structures, Materials and Life Safety ${ }^{4}-$ Technical Evaluation and Application*.

THE CENTER FOR COMPUTER SCIENCES AND TECHNOLOGY conducts research and provides technical services designed to aid Government agencies in improving cost effectiveness in the conduct of their programs through the selection, acquisition, and effective utilization of automatic data processing equipment; and serves as the principal focus within the executive branch for the development of Federal standards for automatic data processing equipment, techniques, and computer languages. The Center consists of the following offices and divisions:

Information Processing Standards-Computer Information-Computer Services - Systems Development-Information Processing Technology.

THE OFFICE FOR INFORMATION PROGRAMS promotes optimum dissemination and accessibility of scientific information generated within NBS and other agencies of the Federal Government; promotes the development of the National Standard Reference Data System and a system of information analysis centers dealing with the broader aspects of the National Measurement System; provides appropriate services to ensure that the NBS. staff has optimum accessibility to the scientific information of the world, and directs the public information activities of the Bureau. The Office consists of the following organizational units:

Office of Standard Reference Data-Office of Technical Information and Publications-Library-Office of International Relations.

${ }_{1}$ Headquarters and Lahoratories at Gaithersburg, Marylind, unless otherwise notrd; mailing address Washington, D.C. 20234.

2 I'art of the Center for Radiation Research.

2 I'art of the Center for Radiation Re
3 Located at Boulder, Colorado 80302 .

- Part of the Center for Bullding 'Technology. 


\section{Carrier Lifetime Measurement by the Photoconductive Decay Method}

Richard L. Mattis and A. James Baroody, Jr.

Institute for Materials Research

National Bureau of Standards

Washington, D.C. 20234

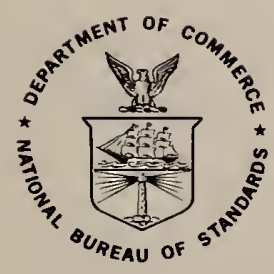

U.S. DEPARTMENT OF COMMERCE, Peter G. Peterson, Secretary NATIONAL BUREAU OF STANDARDS, Lawrence M. Kushner, Acting Director, Issued September 1972 
National Bureau of Standards Technical Note 736

Nat. Bur. Stand. (U.S.), Tech. Note 736, 52 pages (Sept. 1972)

CODEN: NBTNAE

For sale by the Superintendent of Documents, U.S. Government Printing Office, Washington, D.C. 20402 (Order by SD Catalog No. C13.46:736). Price 50 cents. 


\section{PREFACE}

The research reported herein was carried out as part of the Joint Program on Methods of Measurement for Semiconductor Materials, Process Control, and Devices. This program was undertaken in 1968 under joint sponsorship by the National Bureau of Standards (NBS) and other government agencies. The program aims to enhance the performance, interchangeability, and reliability of discrete semiconductor devices and integrated circuits through improvements in methods of measurement for use in specifying materials and devices and in control of device fabrication processes. In particular, this report is intended to assist in the understanding and use of the measurement of carrier lifetime by the photoconductive decay (PCD) method.

The authors are indebted to many people at NBS for assistance in carrying out this research. W. E. Phillips and W. M. Bullis provided helpful suggestions throughout the course of the work. The lifetime versus temperature data were taken by F. R. Kelly. The specimen temperature versus specimen current data were taken by F'. H. Brewer. Fabrication assistance was provided by A. W. Stallings. The manuscript was typed at various stages by T. A. Schultz, R. E. Joel, M. L. Stream, and K. E. Dodson.

The authors are also indebted to $\mathrm{Dr}$. H. Benda for supplying a preprint of his publication which is referenced herein. 

1. INTRODUCTION .................... 2

2. DEFINITION OF LIFETIME ................ 2

3. THE PCD METHOD .................... . . 2

4. BULK DECAY TIME CALCUlATION .................. 3

5. BASIC LIMITATIONS

5.1. Excess Carrier Density . . . . . . . . . . 6

5.2. Light Source . . . . . . . . . . . . . 10

5.3. Inhomogeneities ................ 11

5.4. Filter Thickness . . . . . . . . . . . . . 14

5.5. Temperature .............. 21

6. OTHER CONSIDERATIONS

6.1. Light Turnoff Time . . . . . . . . . . . . 21

6.2. Series Resistance .............. 23

6.3. Specimen Current, Illumination Pattern and

6.4. Specimen Current and Ohmic Heating . . . . . . . . . . 35

6.5. Specimen End Contacts ............ 32

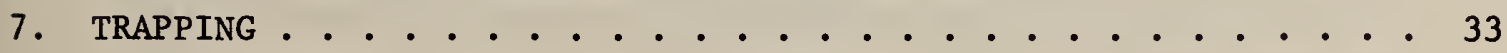

8. SUMMARY ............................ 34

9. REFERENCES ....................... 36

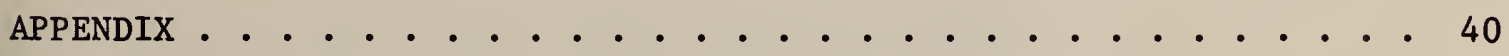


1. Schematic diagram of apparatus used in the PCD method . . . 4

2. Bulk decay time $\tau_{B}$ in microseconds as a function of relative excess carrier density $\Delta n / p_{0}$ for six specimens, where $\tau_{B}$ has been multiplied by $\left(1+\Delta \mathrm{n} / \mathrm{p}_{0}\right)$ so that the plot may be compared with the linear behavior described by eq (4) . . . . 8

3. Cross-section of a $10 \Omega \cdot \mathrm{cm}, n$-type silicon crystal showing the original locations of ten cut specimen ........ 12

4. Illustration of the illumination pattern used to study inhomogeneities in specimen SS13 .......... 19

5. Bulk decay time in microseconds as a function of temperature in degrees Celsius for four specimens.......... 22

6. Photoconductive decay time $\tau_{P C D}$ as a function of turnoff time $t_{\text {off }}$ for five specimens where both $\tau_{P C D}$ and $t_{\text {off }}$ have been normalized with respect to the average TPCD which was measured before turnoff affected the measurement $\bar{\tau}_{P C D}$. . . . . . . 24

7. Photoconductive decay time ${ }^{\tau} \mathrm{PCD}$, signal level $\mathrm{V}_{\text {sig }}$, and percent standard deviation $s$ as a function of series resistance $R_{S}$ for four specimens .................. 
1. Signal Level at Which a Relative Sample Standard Deviation of 4 Percent Was Observed in $\tau_{P C D}$ Measurements on Six

Specimens . . . . . . . . . . . . . . . . . . 9

2. Comparison of Photoconductive Decay Times Measured with

Chopped Light and Pulsed Light Excitation . . . . . . . . . 9

3. Decay Times of Specimens Cut from a $10 \Omega \cdot \mathrm{cm}, n$-Type

Silicon Crystal . . . . . . . . . . . . . . . . 13

4. Decay Times of a Specimen Cut from a $4 \Omega \cdot \mathrm{cm}, p$-Type Silicon Crystal as a Function of Specimen Size . . . . . . . 15

5. The Effect of Filters of Different Thicknesses on the Photoconductive Decay Time $\tau_{\mathrm{PCD}}$ Measured with Chopped

Light Excitation . . . . . . . . . . . . . . . . 16

6. The Effect of Filters of Different Thicknesses on the Photoconductive Decay Time $\tau_{P C D}$ Measured with Pulsed Light Excitation . . . . . . . . . . . . . . . . 17

7. Photoconductive Decay Time of Specimen SS13 Measured with the Illumination Incident at Several Locations on Side A . . . 20

8. Photoconductive Decay Time of Specimen SS13 Measured with the Illumination Incident on Sides $B$ and $D$ for Various Filter Thicknesses . . . . . . . . . . . . . 20

9. Number of Drift Lengths from Each End Contact at Which Sweep-out First Appeared for a Group of Specimens . . . . . . . . . . . . . . . . . . . 29

10. Power Dissipations at Which Specimen Temperature Increased $0.25^{\circ} \mathrm{C}$ for a Group of Twelve Specimens . . . . . . . 31

11. Specimen Characteristics . . . . . . . . . . . . . . . 40 


\section{LIST OF SYMBOLS}

Unless otherwise noted in the text, physical quantities described in this paper are given in the units defined by the International System of Units (SI units) as defined by the General Conference on Weights and Measures in 1960. The SI base units encountered in this report are the metre, the second, and the ampere. Other SI derived units are the volt and the ohm. Where SI base units are not used in favor of centimetre, millimetre, microsecond or degree Celsius, the units are given in the text.

In some instances the strict adherence to SI units may represent a departure from the common parlance of the semiconductor industry. Examples of this are carrier concentrations in atoms per cubic metre and the use of square metres per second for diffusion coefficient. In most of these cases, however, the equations in which these quantities occur are such that the units cancel, thereby making it possible to substitute cgs units for SI units.

Following is a list of symbols used in the report along with the appropriate units.

D ambipolar diffusion coefficient, square metres per second

$\mathrm{D}_{\mathrm{n}}$ diffusion coefficient for electrons, square metres per second

$D_{\mathrm{p}}$ diffusion coefficient for holes, square metres per second

d drift length, metres

E electric field intensity, volts per metre

e base of natural logarithms

$i_{s} \quad$ specimen current, amperes

L specimen length, metres

$\mathrm{L}_{\mathrm{c}}$ distance between illumination boundary and nearest end contact, metres

$\mathrm{L}_{\mathrm{D}} \quad$ ambipolar diffusion length, metres

$\mathrm{L}_{i} \quad$ length of illuminated region, metres

$\mathrm{n}_{0}$ equilibrium electron density, electrons per cubic metre

$\Delta \mathrm{n}$ excess electron density, electrons per cubic metre

$\mathrm{P}_{0} \quad$ equilibrium hole density, holes per cubic metre

$\Delta \mathrm{p} \quad$ excess hole density, holes per cubic metre viii 
R specimen bulk resistance, ohms

$\mathrm{R}_{\mathrm{c}} \quad$ contact resistance, ohms

$\mathrm{R}_{\mathrm{S}} \quad$ series resistance, ohms

r specimen radius, metres

s relative sample standard deviation, percent

T specimen thickness, metres

$t_{\text {off }}$ light turnoff time, seconds

$\Delta V \quad$ change in specimen voltage corresponding to an excess carrier density $\Delta \mathrm{n}=\Delta \mathrm{p}$, volts

$\mathrm{V}_{0} \quad \mathrm{dc}$ voltage across illuminated portion of the specimen, volts

$V_{\text {sig }}$ peak value of PCD signal, volts

$\mathrm{V}_{\text {sig }}{ }^{*}$ value of $\mathrm{V}_{\text {sig }}$ measured for the case $\mathrm{R}_{s} / \mathrm{R}=20$, volts

W specimen width, metres

$\mathrm{x}$ position coordinate for illumination of specimen SS13, millimetres

$\mu \quad$ ambipolar mobility, square metres per volt-second

$\mu_{\text {maj }}$ mobility of majority carriers, square metres per volt-second

$\mu_{\text {min }}$ mobility of minority carriers, square metres per volt-second

$\mu_{\mathrm{n}} \quad$ mobility of electrons, square metres per volt-second

$\mu_{p} \quad$ mobility of holes, square metres per volt-second

$\rho \quad$ specimen resistivity, ohm-metres

$\tau \quad$ carrier lifetime, seconds

$\tau_{B} \quad$ bulk decay time, seconds

${ }^{\tau} P C D$ photoconductive decay time, seconds

${ }^{\tau} P C D$ value of ${ }^{\tau} P C D$ for the case $R_{S} / R=20$, seconds

$\bar{\tau}_{P C D} \quad$ value of $\tau_{P C D}$ when $t_{\text {off }} \ll \tau_{P C D}$, seconds

$\tau_{0} \quad$ carrier lifetime when $\Delta \mathrm{n}=\Delta \mathrm{p}=0$, seconds

$\tau_{\infty} \quad$ carrier lifetime when $\Delta \mathrm{n}=\Delta \mathrm{p} \gg \mathrm{n}_{0}, \mathrm{p}_{0}$, seconds 

Carrier Lifetime Measurement by the

Photoconductive Decay Method

Richard L. Mattis

and

A. James Baroody, Jr.

\section{ABSTRACT}

The photoconductive decay (PCD) method of carrier lifetime measurement is discussed with emphasis on experimental and analytical work done at NBS. The relationship between photoconductive decay time $\tau_{P C D}$, bulk decay time $\tau_{B}$, and lifetime is described briefly and the PCD method is summarized. The determination of $\tau_{B}$ from $\tau_{P C D}$ and the influence of higher modes of recombination are discussed.

Experimental data, supported by theoretical considerations, are presented to demonstrate the dependence of $\tau_{P C D}$ on excess carrier density, the type of light source, specimen homogeneity, filter thickness, and temperature. The dependences of ${ }^{\top} P C D$ on excess carrier density and temperature are consequences of the statistics of the recombination process. Measurements made with chopped light excitation are shown to be less in error due to higher modes of recombination than are measurements made with pulsed light excitation. The presence of inhomogeneities is verified in two crystals. Use of a filter is also shown to reduce the influence of higher modes. An unexpected reduction in $\tau_{P C D}$ with increasing filter thickness is shown to be caused by an inhomogeneity.

Other experimental conditions are discussed as they affect the measurement of ${ }^{T_{P C D}}$. It is shown that the light turnoff must be sufficiently fast and the series resistance sufficiently large that they do not interfere with the measurement. Equations are developed whereby the specimen current and illumination pattern can be chosen such that carrier sweep-out at the ends of the specimen and ohmic heating are avoided. The end contacts must be sufficiently ohmic that excessive contact resistance does not interfere with the measurement.

Trapping is defined and the means for identifying it are discussed briefly. The PCD method is inappropriate for determining minority carrier lifetime when trapping is present or under other circumstances when the hole and electron lifetimes are unequal. icon.

Key Words: Carrier lifetime; germanium; photoconductive decay; si1- 


\section{INTRODUCTION}

In 1965, the National Bureau of Standards (NBS) initiated a study of methods for measuring carrier lifetime in semiconductor crystals. Prior to the present report an annotated bibliography of lifetime measurement was compiled [1], and a preliminary report that described several procedures for the measurement was prepared [2]. A principal phase of the study involved a detailed investigation of the photoconductive decay (PCD) method. This paper summarizes the experimental and analytical work relevant to the $\mathrm{PCD}$ method which has been done since the publication of the earlier report.

The PCD method was studied in detail because of its wide acceptance and its adoption as a standard by both the Institute of Electrical and Electronics Engineers (IEEE) [3] and the American Society for Testing and Materials (ASTM) [4]. The present report provides the technical basis for changes which are being proposed for incorporation into a revision of the ASTM standard.

The relative two-sigma precision [5] for the measurement is quoted in the ASTM standard as \pm 50 percent for germanium and \pm 135 percent for silicon. One objective of the lifetime study was to identify the causes of this poor precision and to develop the technology necessary to improve the precision of the measurement. A multi-laboratory round-robin experiment to test the proposed changes is being planned by ASTM Committee F-1 on Electronics.

\section{DEFINITION OF LIFETIME}

Minority-carrier lifetime is defined as "the average time interval between the generation and recombination of minority carriers in a homogeneous semiconductor" [6]. Rather than attempting to evaluate the lifetime as defined, the emphasis in this report is on the time constant of carrier decay (photoconductive decay time, $\tau_{\mathrm{PCD}}$ ) and the bulk decay time, $\tau_{B}$. Whereas $\tau_{P C D}$ is influenced by recombination at the surface as well as in the bulk, ${ }_{\tau_{B}}$ is derived from ${ }^{\mathrm{B}} \mathrm{PCD}$ and is a time constant of bulk recombination. In the case of simple bulk recombination through a single center, the carrier decay is exponential and the bulk decay time is equal to the bulk minority carrier lifetime. In general, however, they may be different [7].

\section{THE PCD METHOD}

In the PCD method [2-4, 8-11] a semiconductor specimen through which a small current is passed is illuminated with radiation of energy near the band gap energy. The excess carriers created increase the conductivity of the specimen which decreases the voltage across the specimen. Under small-signal conditions, the specimen voltage change and excess carrier density are inversely proportional. The time constant of the increase of the specimen voltage when the light is abruptly removed is the photoconductive decay time, ${ }^{2} \mathrm{PCD}$. 
The experimental apparatus is shown schematically in figure 1 . The light source may be either a pulsed light source, such as a xenon flash tube or other spark source, or a mechanically chopped, steady light source, such as a tungsten filament lamp or other suitable lamp. Light from the source is directed to the specimen by a system of lenses or mirrors. The filter, of the same material as the specimen, absorbs nonpenetrating light so that the carriers are generated more uniformly throughout the specimen volume. The mask limits the illumination to the desired region of the specimen. Current is passed through the specimen by means of ohmic contacts at each end. The specimen voltage is amplified and displayed on an oscilloscope.

Two methods of measuring the photoconductive decay time were studied. In the first method, the PCD curve is matched to an exponential curve inscribed on the oscilloscope graticule by adjusting the sweep rate of the oscilloscope. A time mark generator is used to measure the time constant of the inscribed curve and hence to determine ${ }^{2} P C D$. In the second method, a differential oscilloscope input is used to match the PCD curve with an electronically generated exponential curve with adjustable time constant. When the time constants of the two curves are equal, a nul1 in the form of a straight line is formed.*

Additional details of the apparatus may be found in the literature $[2-4,8-11]$.

\section{BULK DECAY TIME CALCULATION}

Specimens measured by the PCD method are usually as-grown crystals or rectangular parallelepipeds cut from these crystals. Cut specimens are usually lapped on each surface to produce surfaces with high surface recombination velocity. If the surface recombination velocity is assumed to be infinite, then carriers recombine immediately upon reaching the surface. The surface recombination is then limited only by the rate of diffusion of carriers to the surface. Under this condition, the relation between $\tau_{P C D}$ and $\tau_{B}$ is given by:

$$
\tau_{B}=\left[\tau_{\mathrm{PCD}}^{-1}-\pi^{2} \mathrm{D}\left(\frac{1}{\mathrm{~W}^{2}}+\frac{1}{\mathrm{~T}^{2}}\right)\right]^{-1}
$$

for the case of a rectangular parallelepiped [12], and by:

$$
\tau_{B}=\left[\tau_{P C D}^{-1}-\pi^{2} D \frac{9}{16 r^{2}}\right]^{-1}
$$

* Preliminary results indicate that although $\tau_{P C D}$ values measured by the time mark method are slightly longer than $\tau_{P C D}$ values measured by the null method the two methods agree to within two sample standard deviations of the measurement. However, to avoid any discrepancies resulting from the use of two techniques, intercomparative measurements should be made using just one technique. 


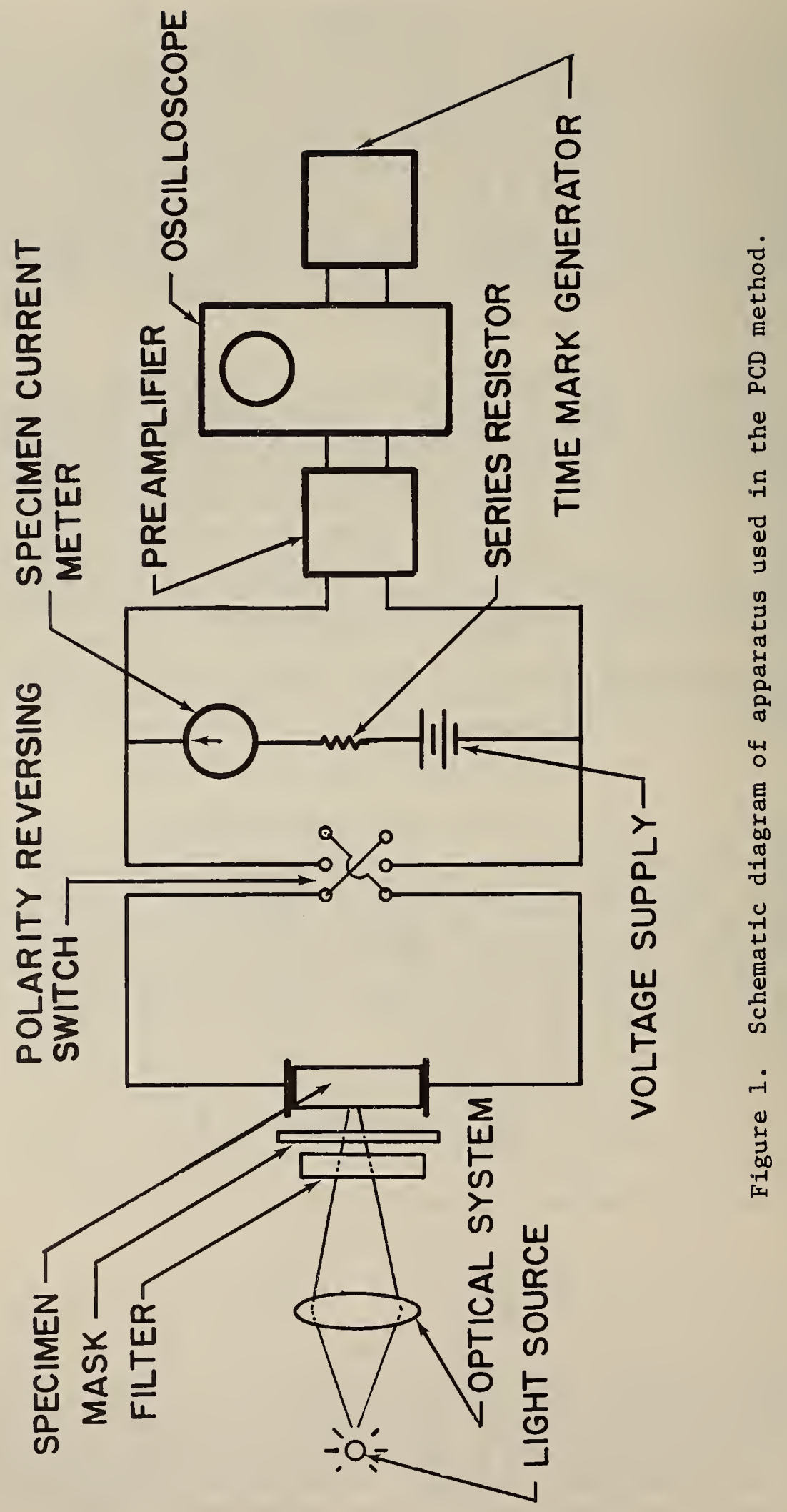


for the case of a right circular cylinder [8]. In these expressions $W$ is the specimen width, $\mathrm{T}$ is the specimen thickness, $\mathrm{r}$ is the specimen radius, and $\mathrm{D}$ is the ambipolar diffusion coefficient given by [13]

$$
D=\frac{D_{n} D_{p}\left(n_{0}+p_{0}\right)}{D_{n} n_{0}+D_{p} p_{0}}
$$

where $\mathrm{D}_{\mathrm{n}}$ and $\mathrm{D}_{\mathrm{p}}$ are the diffusion coefficients of electrons and holes, and $n_{0}$ and po are the equilibrium electron and hole concentrations. For extrinsic materials, $D$ reduces to the minority carrier diffusion coefficient.

Several assumptions are made in deriving eqs (1) and (2). First, it is assumed that the specimen can be characterized by a single bulk decay time. The process of crystal growth often produces an inhomogeneous distribution of flaws and impurity centers which causes $\tau$ to vary with position in the crystal. This can result in poor measurement reproducibility unless the same portion of the specimen is illuminated consistently. This variability is discussed further in section 5.3 .

A second assumption is that the surface recombination velocity is very large over the entire specimen surface. As already indicated this condition can be approximated if a lapped surface is used.

A third assumption is that higher modes or recombination [14] can be neglected. In a manner resembling the Fourier analysis of a waveform, the carrier recombination can be assumed to consist of a series of modes of recombination. In this series each mode is characterized by a time constant and an initial amplitude. As decay proceeds, the modes representing surface decay contribute less and less to the total recombination. Because of the higher rate of recombination at a lapped surface, and the resulting depletion, the contribution of surface recombination to the total recombination process changes as recombination progresses. For example, if decay begins from a uniform excess carrier distribution, those carriers within a diffusion length of the surface dominate the initial stages of decay. In the later stages of decay a smaller fraction of the total recombination takes place at the surface. The influence of higher modes is affected by such experimental parameters as the type of light source and filter thickness as discussed elsewhere in this report. The significance of higher modes can be reduced to a negligible effect by an appropriate choice of these experimental conditions.

A fourth assumption is that of small-signal conditions such that conductivity modulation is not significant [2]. This condition can be met by an appropriate choice of signal level.

A fifth assumption is that photoinjected carriers do not diffuse or drift to the end contacts. If recombination occurs at the end contacts, eqs (1) and (2) must be modified to include a term involving the specimen length or a term involving the applied electric field or both. This 
assumption and the conditions under which it is valid are discussed in section 6.3 .

A sixth assumption is that trapping is not significant so that the electron and hole lifetimes are equal. The effects of trapping and unequal hole and electron lifetime are discussed in section 7 .

When these six assumptions are valid $\tau_{B}$ can be calculated from $\tau_{P C D}$ using eqs (1) and (2). However, in instances where surface recombination is dominant such that $\tau_{B}>3 \tau_{P C D}$, $\tau_{B}$ may be imprecise since it is calculated from the difference between two large numbers. A possible inaccuracy also occurs since $\tau_{B}$ is then sensitive to $D$, the assumed value of which may be in error.

\section{BASIC LIMITATIONS}

Carrier lifetime is dependent upon a number of quantities and conditions which are inherent in the nature of semiconductor materials and the recombination process. These quantities and conditions include excess carrier density, the type of light source, specimen homogeneity, filter thickness, and temperature. The effect of these quantities and conditions upon the measurement of ${ }^{T} P C D$ is discussed in this section. Specimens for which data are recorded in support of the discussion are identified in the Appendix.

\subsection{Excess Carrier Density}

Recombination in silicon and germanium occurs primarily through recombination centers with energy states in the forbidden gap. These energy states result from the presence of foreign impurity atoms or other defects in the material. If the characteristics of these energy states are known, it is possible to predict theoretically the dependence of the lifetime on excess carrier density and temperature in a given specimen. Correction factors could then be determined to deduce the lifetime at some reference excess carrier density and temperature from the lifetime measured at an arbitrary excess carrier density and temperature.

In practice it is very difficult to characterize the recombination centers in a given specimen. Mathematical models have been developed which describe the recombination process under certain idealized conditions. One such model was developed independently by Shockley and Read [15] and by Hall [16]. According to the Shockley-Read-Hall (SRH) recombination model the lifetime $\tau$ is related to the excess carrier density $\Delta \mathrm{n}$ (assumed equal to $\Delta \mathrm{p}$ ) by

$$
\tau\left[1+\frac{\Delta \mathrm{n}}{\mathrm{n}_{0}+\mathrm{p}_{0}}\right]=\tau_{0}+\tau_{\infty}\left[\frac{\Delta \mathrm{n}}{\mathrm{n}_{0}+\mathrm{p}_{0}}\right],
$$

where $\tau_{0}$ is the lifetime in the limit as $\Delta \mathrm{n}$ approaches zero, and $\tau_{\infty}$ is the lifetime in the limit as $\Delta \mathrm{n}$ approaches infinity. 
Data indicating that $\tau_{P C D}$ may be a function of excess carrier density has been reported by many authors $[2,10,17-20]$. The observed dependence was usually greatest in p-type silicon. Although the linear relationship of eq (4) is sometimes observed [18], experimental data of $\tau_{\mathrm{PCD}}$ as a function of $\Delta \mathrm{n}$ more often give a non-linear plot $[10,17,19$, 20]. This indicates that the recombination process of most specimens is too complex to be described by the relatively simple SRH model. An extensive discussion of the SRH model is given by Blakemore [21]. The same work provides an introduction to more complicated recombination models.

Under small-signal conditions, the excess carrier density $\Delta \mathrm{n}$ is proportional to the change in voltage across the specimen $\Delta V$. Since ${ }^{\tau} P C D$ depends on the excess carrier density, and since $\Delta V$ depends on the illumination intensity, a specimen may exhibit a dependence of $\tau_{P C D}$ on illumination intensity.

In order to verify the extent of the excess carrier density dependence, the bulk decay time of several specimens was measured as a function of PCD signal amplitude. The relative excess carrier density was then calculated from [2]:

$$
\frac{\Delta \mathrm{n}}{\mathrm{p}_{0}}=-\frac{\Delta \mathrm{V}}{\mathrm{v}_{0}} \frac{\mu_{\mathrm{p}}}{\mu_{\mathrm{n}}+\mu_{\mathrm{p}}}
$$

where $\mu_{n}$ and $\mu_{p}$ are the mobilities of electrons and holes, $V_{0}$ is the dc voltage across ${ }^{p}$ the illuminated portion of the specimen and $\Delta V$ is the signal level at which $\tau_{P C D}$ was measured. Equation (5) is valid for $p$-type material; an analogous expression is applicable to $n$-type material. In these measurements $\tau_{P C D}$ was evalauted after 75 percent of the carriers had decayed; therefore $\Delta V$ was one-fourth the total PCD signal amplitude. The data from this experiment, shown in figure 2, illustrate the extent of the variation in $\tau_{B}$ with excess carrier density. These results are comparible with similar experiments which have been reported [10, 17-20].

Because no relationship is known for predicting the excess carrier dependence of a particular specimen, it is necessary that the measurement be made at a specified signal level. An experiment was set up to determine what signal levels might be appropriate. Six specimens were selected on which ${ }^{\text {PCD }}$ was measured three times for each specimen current polarity at each of several signal levels. Three percent standard deviations of the measurement at each signal level were calculated: for the three measurements taken at each current polarity and for all six measurements combined. For each specimen a plot was made of these percent standard deviations as a function of signal level. For each plot, the point distribution suggested an envelope below which 90 percent of the points were located. The signal level at which this envelope gave a standard deviation of 4 percent was judged to be suitable for PCD measurements. The six specimens and the corresponding signal levels at which a standard deviation of 4 percent was observed are given in table 1 . For smaller signal levels a larger percent standard deviation was observed. 


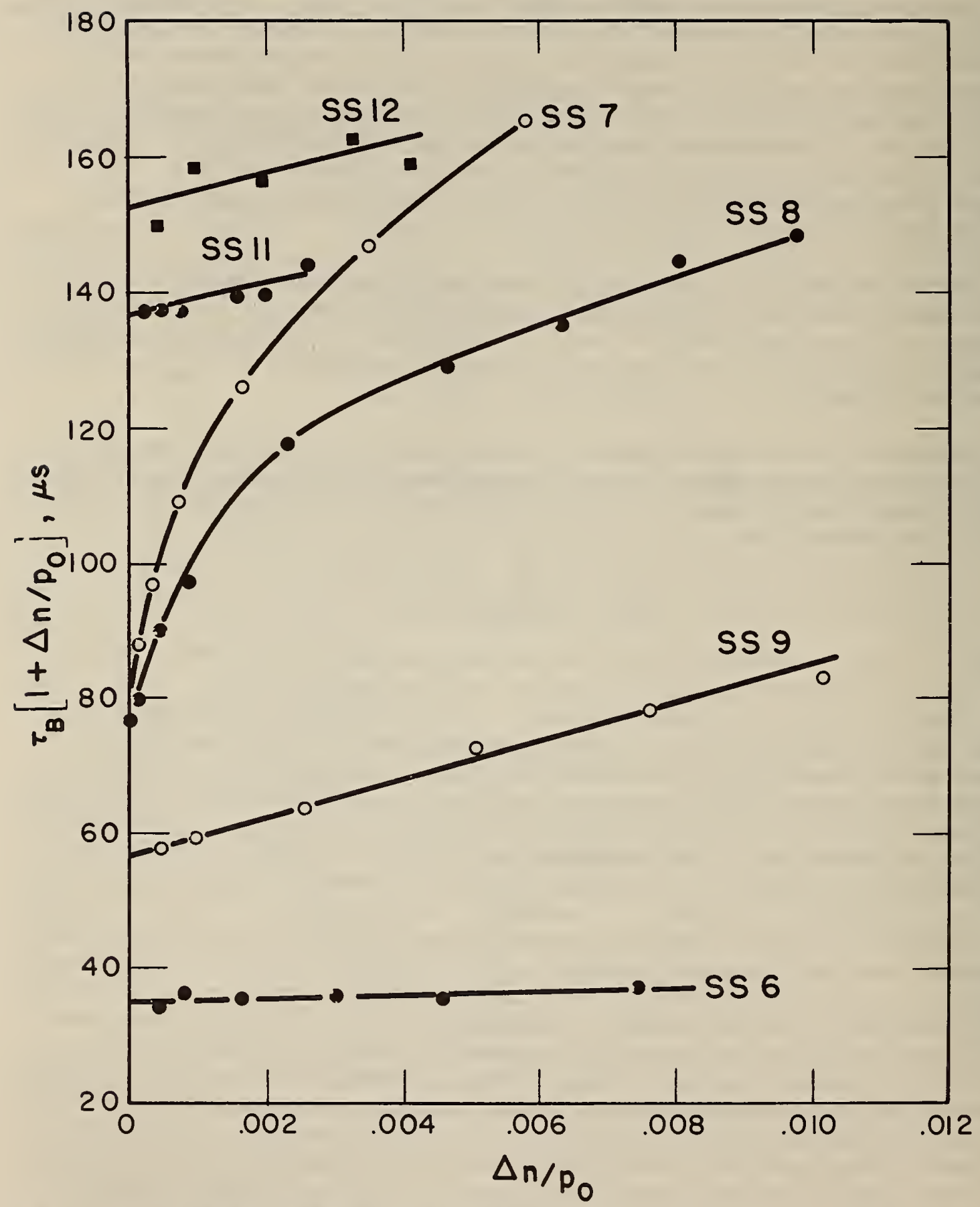

Figure 2. Bulk decay time ${ }{ }_{B}$ in microseconds as a function of relative excess carrier density $\Delta \mathrm{n} / \mathrm{p}_{0}$ for six specimens, where $\tau_{B}$ has been multiplied by $\left(1+\Delta n / p_{0}\right)$ so that the plot may be compared with the linear behavior described by eq (4). 


\section{Table 1 - Signal Level at Which a Relative \\ Sample Standard Deviation of 4 Percent Was Observed in $\tau_{\text {PCD }}$ Measurements on Six Specimens.}

$\begin{array}{lc}\text { Specimen } & \text { Signal Leve1, mV } \\ \text { SS8 } & 8.8 \\ \text { SS18 } & 0.36 \\ 452 D & 1.68 \\ 678 \mathrm{c} / 1 & 0.6 \\ 16444 / 2 & 3.0 \\ 12-620-3 & 2.8\end{array}$

Table 2 - Comparison of Photoconductive

Decay Times Measured with Chopped

Light and Pulsed Light Excitation

Specimen

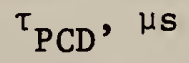

Percent Difference

$$
\text { Chopped Light Pulsed Light }
$$

SS8

73.6

67.6

8.2

SS11

83.2

71.4

14.2

SS14

84.4

77.2

8.5

NBS -13

174 .

155.

10.9

$777 \mathrm{E}$

91.6

84.0

8.3 
The variability of the signal levels recorded in table 1 made it difficult to determine a signal level which would be suitable for all specimens. One approach is to combine this information with the results of sections 6.3. and 6.4. concerning choice of specimen current and to calculate a suitable signal level based on a selected value of relative excess carrier density. For example, for a relative excess carrier den-

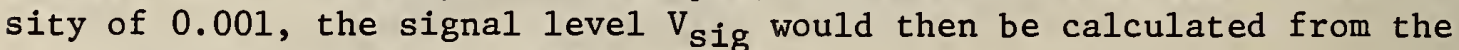
following relationship based on eq (5):

$$
V_{\text {sig }}=4 \Delta V=(4)(0.001) \frac{\mu_{\text {min }}+\mu_{\text {maj }}}{\mu_{\text {maj }}} \frac{L_{i}}{L_{1}} i_{s} \text {, }
$$

where $\mathrm{L}$ is the specimen length, $\mathrm{L}_{i}$ is the length of the illuminated portion of the specimen, and $R$ is the bulk (excliding contact) resistance of the specimen and $i_{s}$ is the specimen current. The factor of 4 accounts for the convention that the decay constant is measured after threefourths of the carriers have decayed. To reduce the time required to calculate $\mathrm{V}_{\text {sig }}$ from eq (6), it is convenient to define a quantity $4\left(\mu_{\min }+\mu_{\text {maj }}\right) / \mu_{\text {maj }}$ as $G_{\mu}$ and tabulate $G_{\mu}$ for each material and type for ready reference. A two-probe resistivity measurement has been found suitable for measurement of $R$. This is discussed further in section 6.4. It should be recognized that in some specimens having low resistivity or large cross-sectional area, the signal level given by eq (6) for a particular choice of $\Delta \mathrm{n} / \mathrm{p}_{0}$ may not be attainable because of limitations of the light source, and a lower signal level would have to be used.

\subsection{Light Source}

There is presently no specification in the standards $[3,4]$ as to whether a chopped or pulsed light source is to be used (although pulsed light is given some preference). Both types are in use at various places in the industry. An experiment was set up to determine the degree of agreement between $\tau_{P C D}$ measurements made with chopped and pulsed light systems. The chopped light system employed a $6-\mathrm{V}, 8-\mathrm{A}$ tungsten ribbon filament lamp as a light source. Light from this source was chopped mechanically at either 14, 45 or $77 \mathrm{~Hz}$. The pulsed light source was a xenon flash tube with an associated $0.05-\mu \mathrm{F}$ capacitor. The capacitor was typically charged to 500 to $1500 \mathrm{~V}$ before the discharge was triggered. The triggering rate was approximately $2 \mathrm{~Hz}$.

Experimental data taken with the two light sources are shown in table 2. For each individual specimen all experimental conditions except the light source were unchanged. A 1-mm thick filter (see sec. 5.4.) was used, and all data were taken by the same operator. Each value is an average of three measurements. The amount by which the pulsed light measurement is less than the chopped light measurement is given as a percent of the average value obtained with chopped light in the fourth column. The sample standard deviation based on each set of three measurements varies from 0.24 to 0.90 percent of the average value for the chopped light measurements and from 0.82 to 2.74 percent for the pulsed light measurements. 
The difference between chopped light and pulsed light measurements is related to the carrier distribution at the beginning of the decay. If light is applied to the specimen for a time equivalent to many lifetimes, as in the case of chopped light, a steady-state excess carrier distribution is established. This does not occur under pulsed light excitation. A theoretical comparison of chopped and pulsed light was presented by Blakemore and Nomura [14] as part of a more general discussion of higher modes of recombination. They showed that the error in ${ }^{2} \mathrm{PCD}$ caused by higher modes is greater for pulsed light excitation than for chopped light excitation under a variety of measurement conditions. An effect of higher modes is thus to produce erroneously short photoconductive decay time measurements under normal experimental conditions when using pulsed light. This conclusion is also supported by a theoretical treatment reported by Ridley [22]. Because of this, it appears that a truer value for ${ }^{\top} \mathrm{PCD}$ is obtained if chopped light rather than pulsed light is used. Also, for the particular apparatus which was used in these investigations, the chopped light measurement was more reproducible than the pulsed light measurement.

\subsection{Inhomogeneities}

Most specimens have dopants and unwanted impurities distributed nonuniformly throughout their volume; this may result in variability of both resistivity and ${ }^{\top} \mathrm{PCD}^{\circ}$. Inhomogeneities in ${ }^{\top} \mathrm{PCD}$ can be detected by making individual measurements with the light incident on different portions of the specimen. This technique is time-consuming and has a spatial resolution limited by the diffusion length or the illumination pattern or both. Schemes have been suggested for detecting longitudinal lifetime inhomogeneities in a filament but these have not gained wide recognition [23-27].

To evaluate the extent of the inhomogeneity of $\tau_{P C D}$, a section of a right circular cylindrical crystal $(10 \Omega \cdot \mathrm{cm}, n$-type silicon) was cut longitudinally into ten specimens each with an approximately square cross-section and a length equal to the length of the original section. The location of the ten specimens within the cross-section of the original crystal is shown in figure 3. (Specimen 1 in fig. 3 is identical with specimen SS13 discussed in sec. 5.4.). The photoconductive decay times of the ten specimens are given in table 3 . These data suggest that $\tau_{B}$ varied by a factor of ten with position in the original crystal and that $\tau_{B}$ was lowest at the crystal center and increased near the crystal surface. Unfortunately the side surfaces of the ten specimens cannot be identified relative to their position in the original crystal section. If this could be done, the inhomogeneity in specimen 1 discussed in section 5.4. might be shown to be consistent with the overall inhomogeneity within the crystal.

In another experiment designed to detect inhomogeneities, a specimen ( $4 \Omega \cdot \mathrm{cm}, p$-type silicon) in the form of a rectangular parallelepiped was cut from the center of a right circular cylindrical crystal. The crosssection of the parallelepiped was reduced several times in succession by lapping. Following each size reduction, a $\tau_{\mathrm{PCD}}$ measurement was made on 


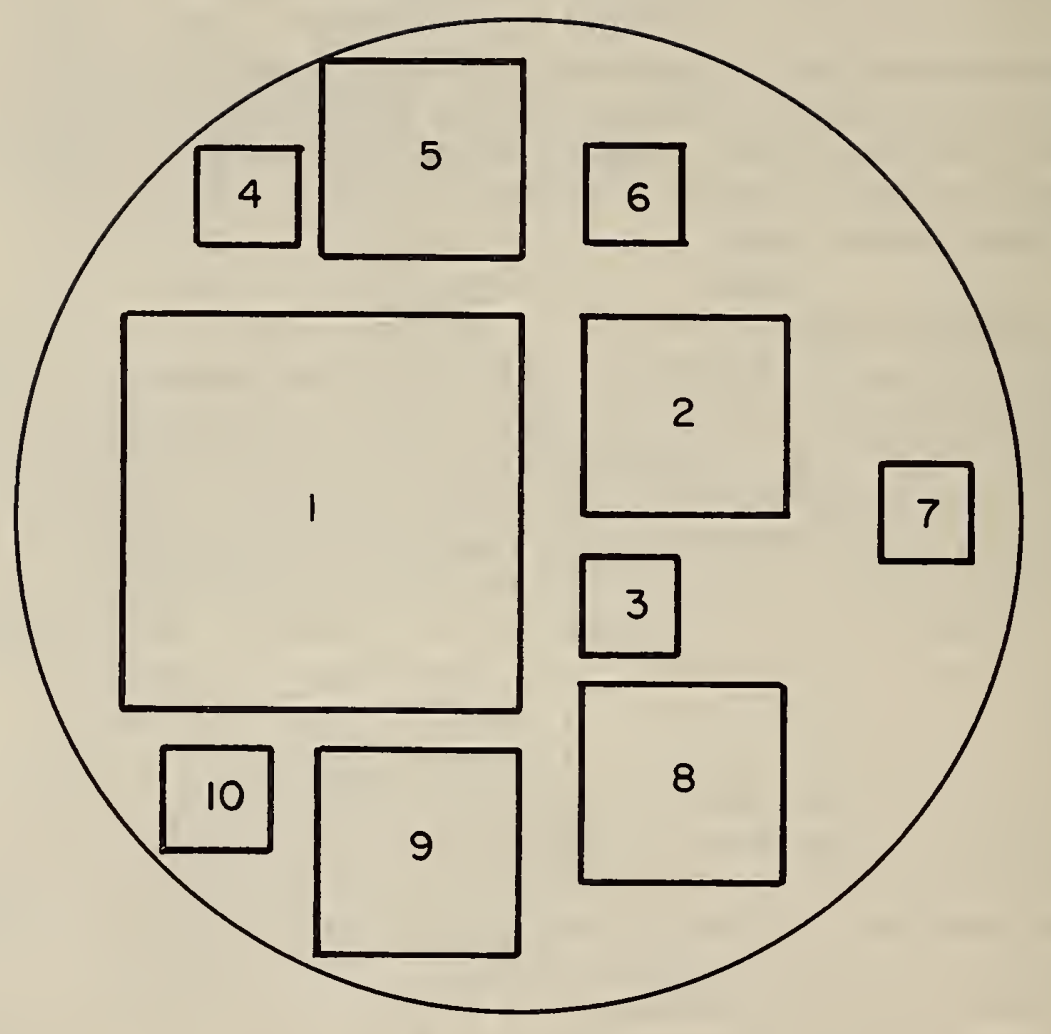

Figure 3. Cross-section of a $10 \Omega \cdot \mathrm{cm}$, $n$-type silicon crystal showing the original locations of ten cut specimens. 


\section{Table 3 - Decay Times of Specimens \\ Cut from a $10 \Omega \cdot \mathrm{cm}, n$-Type Silicon Crystal.}

$\begin{array}{cccr}\begin{array}{c}\text { Specimen } \\ \text { (see fig. 3) }\end{array} & \begin{array}{c}\text { Cross-section, } \\ \mathrm{cm} \text { by } \mathrm{cm}\end{array} & { }^{\tau}{ }_{\mathrm{PCD}}, \mu \mathrm{s} & \tau_{\mathrm{B}}, \mu \mathrm{s} \\ 1 & 1.002 \text { by } 0.998 & 132 & 137 \\ 2 & 0.499 \text { by } 0.497 & 84 & 91 \\ 3 & 0.251 \text { by } 0.249 & 65 & 86 \\ 4 & 0.246 \text { by } 0.248 & 233 & 2500 \\ 5 & 0.498 \text { by } 0.503 & 494 & 947 \\ 6 & 0.246 \text { by } 0.247 & 208 & 1110 \\ 7 & 0.249 \text { by } 0.254 & 240 & 2500 \\ 8 & 0.498 \text { by } 0.503 & 193 & 237 \\ 9 & 0.502 \text { by } 0.502 & 518 & 1030 \\ 10 & 0.248 \text { by } 0.246 & 231 & 2330\end{array}$


the specimen. The data from this experiment are shown in table 4. The decrease in $\tau_{B}$ which was measured for successively smaller specimen cross-sections suggests that the bulk decay time of the original crystal increased with distance from the center. The increase in $\tau_{B}$ between the sixth and seventh readings resulted from changes in recombination characteristics caused by accidental heating during a drift mobility measurement rather than any change in cross-section. Presumably the heating annealed out some of the recombination centers causing an increase in the Iifetime.

In interpreting a PCD measurement, it must be understood (1) that the $\tau_{B}$ value represents an average over the illuminated region, and (2) that different $\tau_{B}$ values might be measured on different portions of the specimen.

\subsection{Filter Thickness}

It is desirable that the incident light penetrate deeply into the specimen so that carriers are generated as uniformly as possible within the bulk. Completely uniform generation is not physically realizable but may be approached by filtering the incident light. A filter is a slice of the specimen material with two parallel polished surfaces. It is placed close to the specimen and oriented so that the polished surfaces are perpendicular to the incident light path. The present standards specify that a filter be used; the IEEE standard [3] specifies that the filter thickness be comparable with specimen thickness, while the ASTM standard [4] specifies that the filter be about $1 \mathrm{~mm}$ thick.

Blakemore and Nomura [14] report the computer synthesis of two decay curves, one of which proceeds from uniform generation (approximating the use of a thick filter) and one of which proceeds from non-uniform generation (approximating the use of no filter). The error in the $\tau_{P C D}$ measurement due to the influence of higher modes is shown to be greater in the case of non-uniform generation.

Other work done specifically on the effects of filters has also been reported. Blakemore [17] suggests the use of the thickest possible filter, yet his data show a difference of only a few percent between photoconductive decay times measured with $0.5-\mathrm{mm}$ thick and 5-mm thick filters and a pulsed light source. Sim [28] recommends the use of a filter 3 to $7 \mathrm{~mm}$ thick and calculates that for a pulsed light source the measurement error which results from not using a filter is between 25 and 50 percent.

To obtain additional data on the influence of a filter, the photoconductive decay time was measured on several specimens. Three different filter thicknesses and either chopped or pulsed light excitation or both were used. The light intensity was adjusted to maintain a constant signal level for each specimen. These data, shown in tables 5 and 6 , indicate that $\tau_{P C D}$ usually is longer when a filter is used, and that a 1-mm thick filter usually gives almost the same result as a thicker filter. The data of tables 5 and 6 also show the effect of the filter to be greater with pulsed light than with chopped light excitation. This is 


\section{Table 4 - Decay Times of a Specimen Cut from \\ a $4 \Omega \cdot \mathrm{cm}$, p-Type Silicon Crystal as a Function of Specimen Size}

$\begin{array}{cccc}\text { Reading } & \begin{array}{c}\text { Cross-section, } \\ \mathrm{cm} \text { by } \mathrm{cm}\end{array} & \tau_{\mathrm{PCD}}, \mu \mathrm{s} & \tau_{\mathrm{B}}, \mu s \\ 1 & 1.003 \text { by } 1.002 & 83 . & 87.7 \\ 2 & 0.999 \text { by } 0.875 & 79.5 & 84.6 \\ 3 & 0.995 \text { by } 0.751 & 75.5 & 81.0 \\ 4 & 0.874 \text { by } 0.750 & 73.5 & 79.3 \\ 5 & 0.753 \text { by } 0.750 & 70.0 & 76.0 \\ 6 & 0.633 \text { by } 0.750 & 68.0 & 74.9 \\ 7 & 0.633 \text { by } 0.750 & 88.1 & 100 . \\ 8 & 0.500 \text { by } 0.749 & 74.0 & 85.5\end{array}$




\section{Table 5 - The Effect of Filters of Different Thicknesses on the Photoconductive Decay Time $\tau_{P C D}$ Measured with Chopped Light Excitation}

Specimen

${ }^{\tau} \mathrm{PCD}, \mu s$
lmm Filter $\quad 5 \mathrm{~mm}$ Filter

10mm Filter

No Filter

1mm Filter $\quad 5 \mathrm{~mm}$ Filter

569.

DOFL

572.

573.

573.

183.

NBS -13

185.

187 .

186.

73.6

SS8

73.3

73.6

74.1

276.

SS10

274 .

277.

278 .

87.7

SS11

88.0

90.1

88.7

85.5

SS14

81.6

84.4

98.7

98.9

$777 \mathrm{E}$

99.2

98.2

1220 .

1240.

$13069 / 3$

1210.

1210.

122.

121.

$14787 / 5$

127.

126.

125.

123.

$15705 / 5$

134.

130.

2160 .

2200 .

52792A

2150.

2200.

1500 .

1500. 


\section{Table 6 - The Effect of Filters of Different Thicknesses on the Photoconductive \\ Decay Time $\tau_{P C D}$ Measured with \\ Pulsed Light Excitation}

Specimen

No Filter

150 .

21.

20.

19.5

45.2

28.7

70.3

58.3

65.3

20.5

$$
\tau_{\mathrm{PCD}}, \mu \mathrm{s}
$$

1mm Filter 5mm Filter

10mm Filter

155.

25.

25.

24.

23.

22.

23.

23.7

22.6

23.4

67.6

67.6

66.8

35.2

34.9

34.8

71.4

77.2

78.4

84.0

16.5

15.0

13.0 
because the decay process for the chopped light cases does not involve higher modes to the same extent as for pulsed light (see sec.5.2.) thereby decreasing the extent to which a filter can further reduce higher mode decay. For most specimens listed in table 5, the measured dependence of $\tau_{\mathrm{PCD}}$ on filter thickness is less than the relative sample standard deviation of chopped light measurements reported in section 5.2. For most specimens listed in table 6 , the percent change in $\tau_{P C D}$ which is observed when comparing measurements made with no filter and measurements made with a $1 \mathrm{~mm}$ filter is greater than the relative sample standard deviation of pulsed light measurements reported in section 5.2. Further increases in filter thickness cause changes in $\tau_{P C D}$ which are small compared with the relative sample standard deviation for pulsed light measurements, however.

Those instances in tables 5 and 6 in which use of a filter resulted in a decreased value of ${ }^{\tau}$ PCD might be caused by the presence of an inhomogeneity. Since the filter thickness determines the distribution of excess carriers within the specimen and so determines the depth at which the typical carrier is generated, an inhomogeneity can cause $\tau_{P C D}$ to be shorter when measured with a thicker filter. Increasing the filter thickness causes the typical excess carrier to be generated closer to the center of the specimen cross-section. If the lifetime of the material decreases with distance into the specimen from the surface, a measurement with a thick filter can give a shorter ${ }^{2} P C D$ value than does a measurement with a thinner filter or with no filter. Conversely, if the lifetime of the material increases with distance into the specimen from the surface, a measurement with a thick filter $c$ an give a longer $\tau_{P C D}$ value than does a measurement with a thinner filter or with no filter.

An example of the effect of a filter on an inhomogeneous specimen was observed in specimen SS13. One of the specimen sides, side A, was illuminated with a rectangle of light $1.25 \mathrm{~cm}$ long and $0.6 \mathrm{~cm}$ wide, as shown in figure 4. The left edge of the lighted region initially touched the $A B$ edge of the specimen. The distance $x$ from the $A B$ edge to the illumination boundary was then increased in $0.5-\mathrm{mm}$ increments until the right edge of the lighted region touched the $\mathrm{AD}$ edge. A measurement of ${ }^{\top}$ PCD was made at each step. The data, shown in table 7 , indicate an increase in $\tau_{P C D}$ in going from the $A B$ edge to the $A D$ edge, verifying that lifetime is inhomogeneous in this specimen. Specimen SS13 was then measured with filters of different thicknesses with light incident on sides $B$ and D. The data, shown in table 8 , illustrate the effect of a filter in the presence of an inhomogeneity. With the light incident on side D, the measurement with the filter was less than the measurement without a filter, while with the light incident on side B the opposite was true. This specimen thus illustrates the behavior described in the previous paragraph.

The data discussed in this section indicate that the effect of a filter on a chopped light PCD measurement is very small if the specimen is homogeneous. Nevertheless, if a $1 \mathrm{~mm}$ filter is used to enhance the uniformity of the excess carrier generation within the illuminated region a larger volume of the specimen is influential in the measurement. 


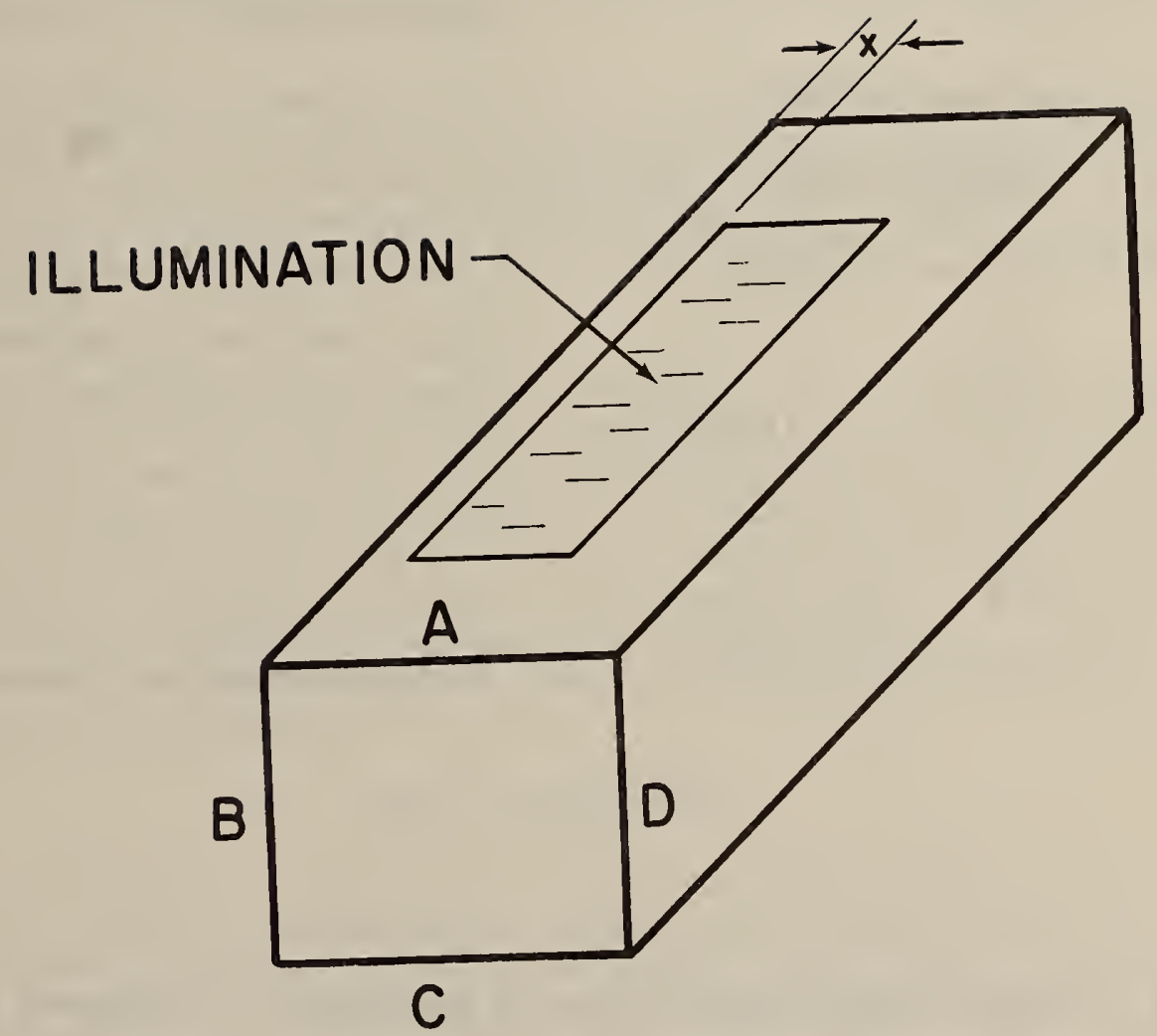

Figure 4. Illustration of the illumination pattern used to study inhomogeneities in specimen SS13. 
Table 7 - Photoconductive Decay Time of Specimen SS13 Measured with the Illumination Incident at Several Locations on Side A

$\mathrm{x}$,

$\mathrm{mm}$

0.0

0.5

1.0

1.5

2.0

2.5

3.0

3.5

4.0
' PCD'

$\mu \mathrm{s}$

99

100

103

108

118

127

143

151

162
Notes

Light adjacent to $A B$ edge

Light centered on specimen 
However, when measuring specimens of low resistivity material with large cross-sectional area, the PCD signal level may be too low to permit the use of a filter. Attainment of the signal level given by eq (6) appears to be more important than the use of a filter.

\subsection{Temperature}

In most specimens, $\tau_{P C D}$ is a function of temperature. This is consistent with the $\mathrm{SRH}$ recombination model [15, 16] as well as more complex models and is discussed by Blakemore [21] and by Susila and Suryan [29]. The temperature dependence is caused by the movement of the Fermi level with respect to the recombination center energy levels. Data of lifetime as a function of temperature have been reported by many authors [18, 19, 30-33].

The photoconductive decay time of several specimens was measured as a function of temperature in order to evaluate the dependence near room temperature. In figure 5 the bulk decay time of these specimens is plotted as a function of temperature near room temperature. The bulk decay time change with temperature ranges from 1 to 5 percent per degree Celsius.

Because a few degrees difference in temperature may cause a significant change in $\tau_{B}$, the precision of the measurement is reduced if the temperature is not maintained constant at a known value or is not corrected for. In theory lifetime-temperature correction factors could be determined from knowledge of the energy level or levels of the recombination centers in a particular specimen. In practice this is difficult to do and temperature correction factors for lifetime cannot generally be given. It is therefore necessary to make intercomparative measurements of ${ }^{\tau} \mathrm{PCD}$ at the same temperature.

\section{OTHER CONSIDERATIONS}

Whereas the previous section dealt with phenomena which are inherent in the nature of semiconductor materials and of the recombination process, this section discusses effects which result from tehcnological problems related to instrumentation and specimen preparation. Light turnoff time, series resistance, specimen current, illumination pattern, and specimen end contacts are discussed as they affect the measurement of $\tau_{\mathrm{PCD}}$

\subsection{Light Turnoff Time}

The light turnoff time must be sufficiently short that it does not interfere with the measurement of ${ }^{\tau}{ }_{P C D}$. In the case of linear light turnoff, such as would be encountered using chopped 1ight, there is no error in the ${ }^{\tau} \mathrm{PCD}$ measurement if it is made any time after the light is completely extinguished $[34,35]$.

For the idealized case of purely linear light turnoff, the turnoff time, $t_{\text {off }}$, is defined as the minimum time between the conditions of 


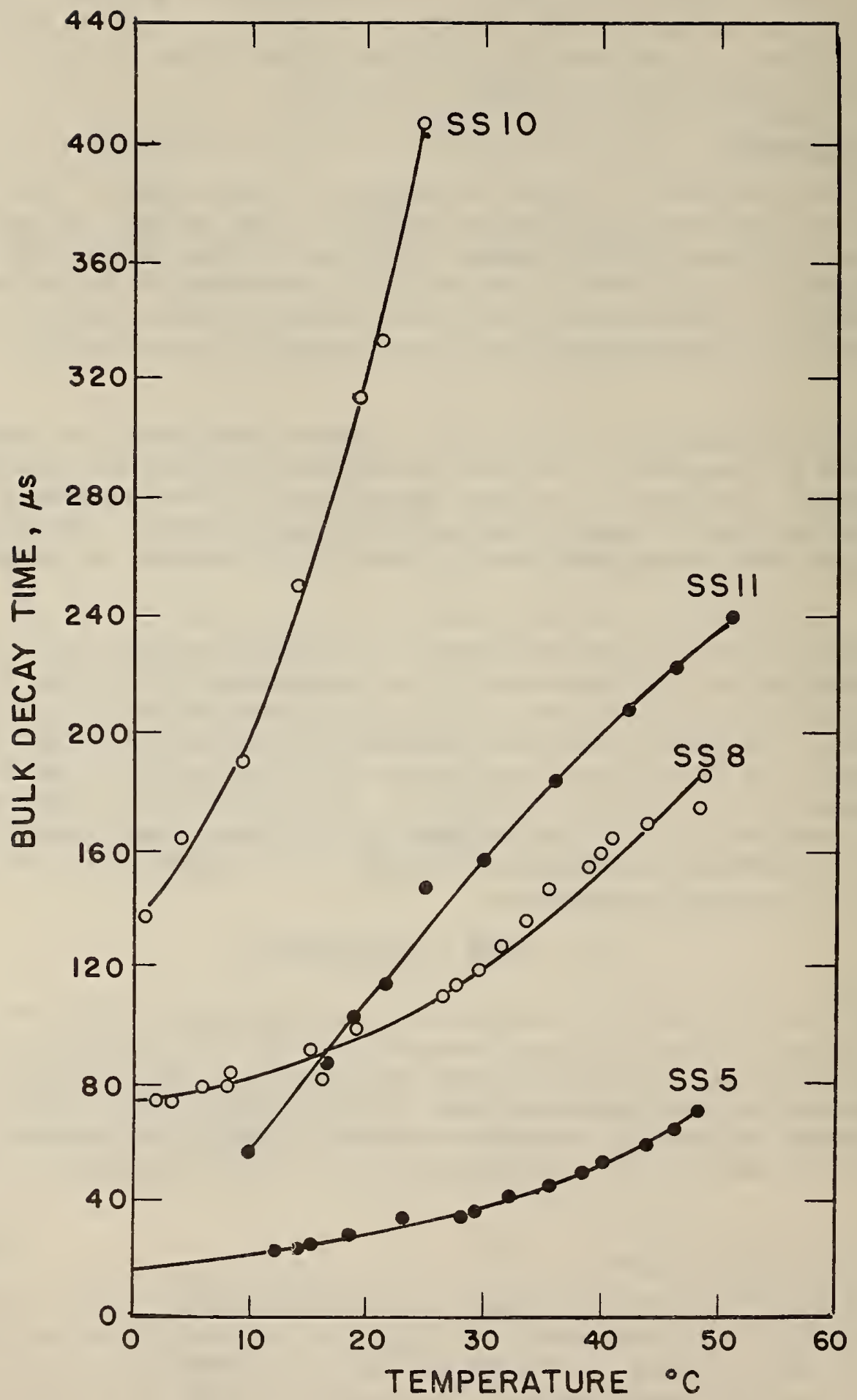

Figure 5. Bulk decay time in microseconds as $a^{*}$ function of temperature in degrees Celsius for four specimens. 
light fully on and light fully off. To determine the effect of turnoff time on the $\tau_{P C D}$ measurement, decay curves for various values of $t_{\text {off }} / \tau_{P C D}$ were synthesized. This analysis revealed that when $\tau_{P C D}$ is measured after 75 percent of the excess carriers have recombined, the ${ }^{\tau} P C D$ measurement is unaffected by light turnoff if $t_{o f f} / \tau_{P C D}$ is less than about 4 .

An experiment was set up to observe the effect of varying the turnoff time and to compare these observations with the theoretical prediction just discussed. By driving the chopper motor with an audio oscillator through a power amplifier, the chopper speed could be controlled by the oscillator frequency. Measurements were made on five specimens in which the $t_{\text {off }} / \tau_{P C D}$ ratio was varied from approximately 1 to 4 . The light turnoff characteristic typically consisted of a linear portion preceded and followed by rounded portions at the initial and final stages of turnoff. The linear portion generally occupied the center half of the turnoff characteristic. In these measurements, $t_{\text {off }}$ was determined by extrapolating the linear portion until it intersected the levels corresponding to light fully on and light fully off and measuring the time between these two intersections. The results, shown in figure 6 , indicate that for values of $t_{\mathrm{Off}} / \bar{\tau}_{\mathrm{PCD}}$ between 2 and 3 , the measured decay time $\tau_{P C D}$ begins to increase from its short-turnoff-time value $\bar{\tau}_{P C D}$. The deviation from the prediction for the idealized case is attributed to the rounding of the initial and final portions of the turnoff charactristic.

In the case of a pulsed source such as a spark gap or xenon flash tube, the decay of light is often irregular. Later stages of the light decay are approximately exponential, and considerable time may be required for the light to extinguish entirely. The extent to which pulsed light turnoff interferes with the measurement is difficult to analyze due to the irregular nature of the light decay. For the apparatus used in this study, the full-width-at-half-maximum (FWHM) pulse width varied from $1.3 \mu \mathrm{s}$ at a discharge voltage of $500 \mathrm{~V}$ to $0.45 \mu \mathrm{s}$ at $1500 \mathrm{~V}$. The corresponding times between initiation of the pulsed light flash and the decay to 5 percent of peak intensity were 7.5 and $5 \mu \mathrm{s}$. This was considered to be the lower limit of measurable photoconductive decay time using this source.

\subsection{Series Resistance}

In the ideal case, a constant current is supplied to the specimen. When this is so and when small-signal conditions prevail, the PCD signal amplitude $\Delta V$ is directly proportional to the excess carrier density $\Delta n$ (see eq (5)). The present standards [3, 4] suggest as adequate a constant voltage power supply in series with a resistance $R_{S}$ which is at least twenty times the specimen resistance $R$. The principal effect of using a constant voltage supply and series resistor $R_{S}$ is to reduce the amplitude of the PCD signal for a given excess carrier density to the fraction $R_{S} /\left(R_{S}+R\right)$ of the value $i t$ would have under constant current conditions. If contact resistance $R_{c}$ is present the above fraction must be modified such that $R$ becomes $R+R_{c}$. 


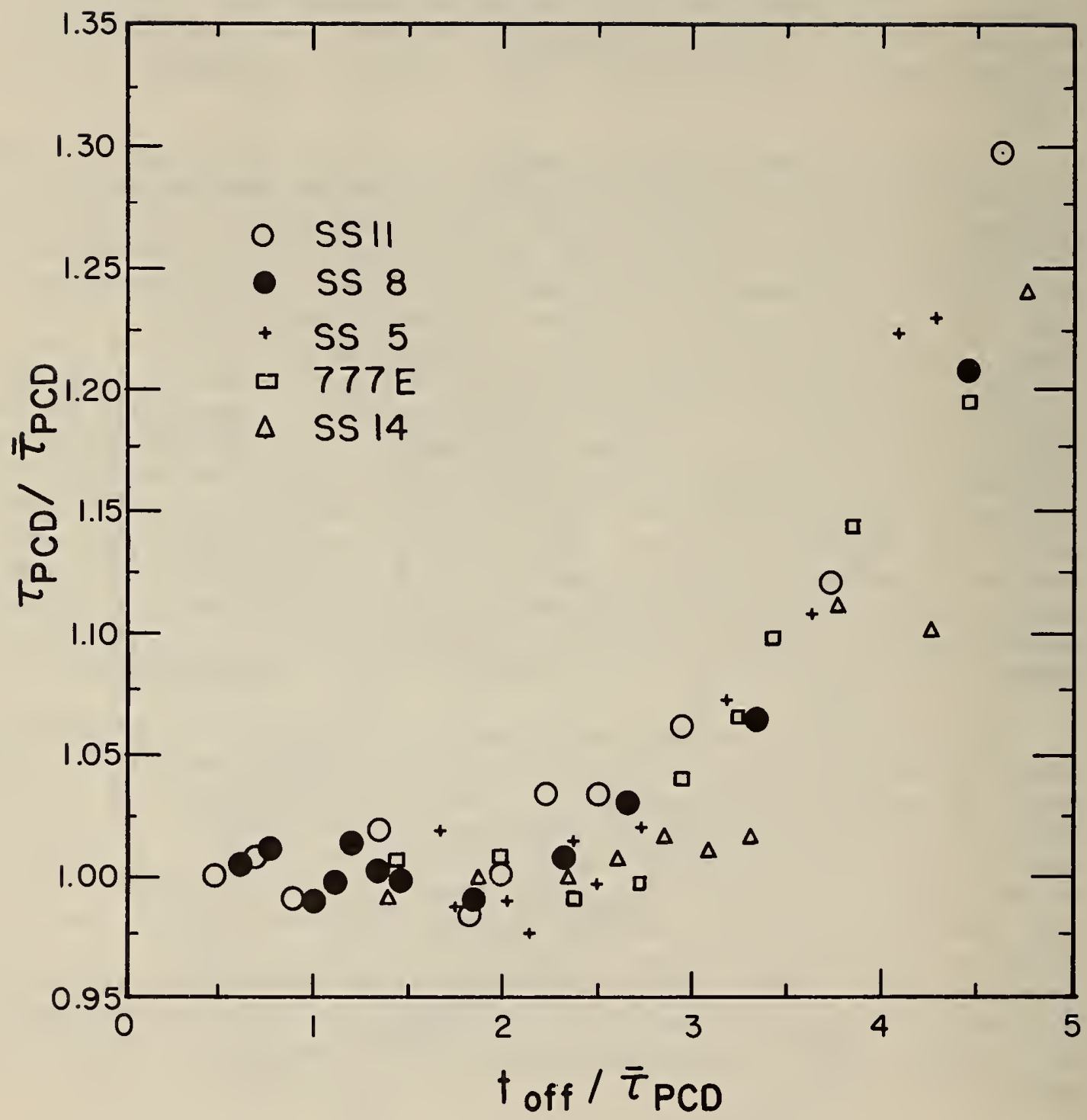

Figure 6. Photoconductive decay time ${ }^{2} P C D$ as a function of turnoff time $t_{\text {off }}$ for five specimens where both $\tau_{P C D}$ and $t_{\text {off }}$ have been normalized with respect to the average $\tau_{P C D}$ which was measured before turnoff affected the measurement ${ }^{\top}$ PCD 
An experiment was performed to verify the predicted behavior of the signal level for various values of series resistance $R_{S}$, and to observe any changes in $\tau_{P C D}$ resulting from changes in $R_{S}$. The experiment was performed on four specimens for which the ratio $R_{S} / R$ was varied between 20 and 0.1 . Al1 measurements on a given specimen were made with the same light intensity. Measured values of ${ }^{\tau}$ PCD and $V_{\text {sig }}$ were normalized with respect to the respective values measured at $R_{S} / R=20$, denoted ${ }^{\tau} P C D^{*}$ and $V_{\text {sig }}{ }^{*}$. The data, summarized in figure 7 , indicate that (1) the standard deviation of the measurement was essentially independent of the ratio $\mathrm{R}_{\mathrm{S}} / \mathrm{R}$ despite the lower signal-to-noise ratio at low $\mathrm{R}_{\mathrm{S}} / \mathrm{R}$ ratios, (2) the signal level decreased as $R_{S} / R$ decreased in good agreement with the relationship mentioned above, and (3) the $\tau_{P C D}$ values were not significantly affected by changes in $R_{S} / R$ for $R_{S} / R \geq 1$. These results suggest that suitable measurements can be made when $R_{S} \geq R$. The effect of series resistance on the signal level should be taken into account in eq (6), however, when the reduction in signal level is significant. The desired value of $V_{\text {sig }}$ would then be obtained by multiplying the right-hand side of eq (6) by $R_{S} /\left(R_{S}+R\right)$.

\subsection{Specimen Current, Illumination Pattern and Sweep-Out}

In order for $\tau_{B}$ and $\tau_{P C D}$ to be related in the manner stated in eqs (1) and (2) it is necessary that photoinjected carriers neither diffuse nor drift to the end contacts. Recombination occurs almost immediately at the end contacts, and such diffusion or drift would result in an erroneously short ${ }^{\mathrm{P} C D}$ measurement.

Stevenson and Keyes [8] studied the case of uniform excess carrier generation throughout an entire specimen in the form of a rectangular parallelepiped. They derived an equation which, expressed in the notation of this report, can be written as:

$$
\tau_{B}=\left[\tau_{P C D}-1-\pi^{2} D\left(\frac{1}{L^{2}}+\frac{1}{W^{2}}+\frac{1}{T^{2}}\right)-\frac{(\mu E)^{2}}{4 D}\right]^{-1},
$$

where $\mathrm{E}$ is the applied electric field and $\mu$ is the ambipolar mobility given by [3]:

$$
\mu=\frac{\mu_{n}^{\mu}{ }_{p}\left|n_{0}-p_{0}\right|}{n_{0} \mu_{n}+p_{0} \mu_{p}} .
$$

In extrinsic material, $\mu$ reduces to the minority-carrier mobility. A similar expression could be written for a right circular cylindrical specimen.

Note the similarity between eqs (1) and (7). The term $\pi^{2} \mathrm{D} / \mathrm{L}^{2}$ in eq (7) represents excess carrier recombination resulting from diffusion to the end contacts. The term $(\mu \mathrm{E})^{2} / 4 \mathrm{D}$ in eq ( 7 ) represents excess carrier recombination resulting from drift to the end contacts under the applied field E. 


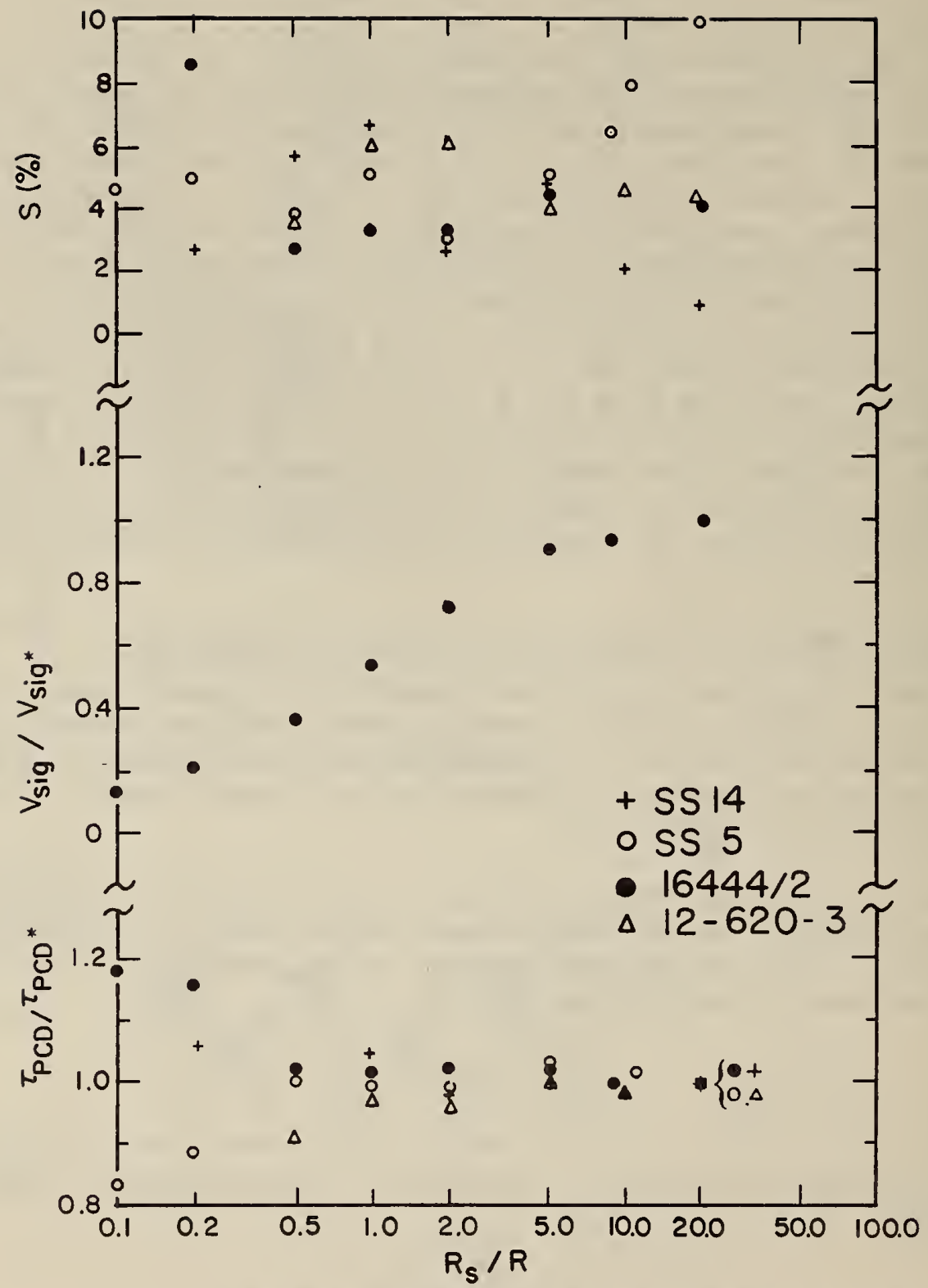

Figure 7. Photoconductive decay time $\tau_{P C D}$, signal level $\mathrm{V}_{\mathrm{sig}}$, and percent standard deviation $s$ as a function of series resistance $R_{S}$ for four specimens. ('Values of $R_{S}$ have been normalized with respect to the specimen resistance $R$. Values of $\tau_{P C D}$ and $V_{\text {sig }}$ have been normalized with respect to the values of $\tau_{P C D}$ and $V_{\text {sig }}$ measured for $\mathrm{R}_{\mathrm{S}} / \mathrm{R}$ equal to 20 , ${ }^{\top} \mathrm{PCD}$ * and $\mathrm{V}_{\text {Sig }}{ }^{*}$, respectively. In the plot of $V_{s i g}$ as a function of $R_{S}$, each specimen followed the same pattern. In the interest of clarity only one set of data is plotted. In the plot of $V_{s i g}$ as a function of $R_{S}$, each specimen followed the same pattern. In the interest of clarity only one set of data is plotted.) 
For the case of uniform generation in the entire specimen, Stevenson and Keyes [8] suggest that the electric field E be such that

$$
\frac{(\mu \mathrm{E})^{2}}{4 \mathrm{D}} \ll \frac{1}{\tau_{\mathrm{B}}}+\pi^{2} \mathrm{D}\left[\frac{1}{\mathrm{~L}^{2}}+\frac{1}{\mathrm{~W}^{2}}+\frac{1}{\mathrm{~T}^{2}}\right] \text {. }
$$

This expression forms the basis for the specification in the standards $[3,4]$ that $E$ be such that

$$
\mathrm{E} \leq \frac{300}{(\mu \tau)^{1 / 2}}
$$

where $E$ is in volts per centimetre, $\mu$ is in square centimetres per voltsecond, and $\tau$ is the lifetime in microseconds.

In practice it is preferable not to illuminate the entire specimen. In the first place, photovoltages which interfere with the measurement are often generated at metal-semiconductor end contacts. In the second place, the calculation of ${ }^{\tau_{B}}$ from ${ }^{\tau_{P C D}}$ is simplified if the regions near the specimen ends are masked from the incident light and the electric field is selected such that photogenerated carriers do not diffuse or drift to the end contacts. To assure this it is necessary that the distance $L_{c}$ between the illumination boundary and the nearest end contact be large compared to both the drift length $d$ and the ambipolar diffusion length $\mathrm{L}_{\mathrm{D}}$. The quantities $\mathrm{d}$ and $\mathrm{L}_{\mathrm{D}}$ are defined by:

$$
\begin{aligned}
\mathrm{d} & =\mu \mathrm{E} \tau_{P C D} \\
\mathrm{~L}_{D} & =\left(D \tau_{P C D}\right)^{1 / 2} .
\end{aligned}
$$

Carrier recombination at the end contacts caused by drift under applied electric field is called sweep-out. The problem of sweep-out is discussed in the IEEE standard [3] and by several authors [2, 9, 36-38].

Based on the definitions of $\tau_{P C D}$ and $d$, one expects that if a steady-state excess carrier density $\Delta \mathrm{n}$ is established in an illuminated region, in a time $T P C D$ the excess carrier distribution drifts under the applied field a distance $d$. At a distance d from the illumination boundary, in the direction of carrier drift, the excess carrier density is reduced from $\Delta \mathrm{n}$ to $\Delta \mathrm{n} / \mathrm{e}$ where $\mathrm{e}$ is the Naperian base. At a distance $4 \mathrm{~d}$ from the illumination boundary one expects an excess carrier density of $\Delta \mathrm{n} / \mathrm{e}^{4} \approx 0.02 \Delta \mathrm{n}$. Presumably, an end contact at a distance $4 \mathrm{~d}$ from the illumination boundary would result in sweep-out of only a small fraction of the total number of excess carriers, and thereby would have an insignificant effect on the measurement of ${ }^{\tau_{\mathrm{PCD}}}{ }$

An experiment was performed to test this hypothesis. The photoconductive decay time was not measured directly, rather changes in ${ }^{\top} P C D$ were detected by measuring steady-state photoconductivity. The steady-state photoconductivity of a specimen is approximately directly proportional to 
the lifetime. Several specimens were scanned with a narrow light beam and their photoconductivity (PC) profiles were plotted on an $\mathrm{x}-\mathrm{y}$ recorder. The specimen current was normally chosen to give a drift length of $1 \mathrm{~mm}$. The diffusion lengths of the six specimens ranged from $0.30 \mathrm{~mm}$ to $1.68 \mathrm{~mm}$, but all specimens except specimen $678 \mathrm{c} / 1$ had a diffusion 1 ength of $0.67 \mathrm{~mm}$ or less. In most instances therefore, $\mathrm{L}_{\mathrm{D}}$ was small compared to $d$. The PC profiles were relatively flat in the center but showed a decrease in photoconductivity near the end contacts. This decrease in photoconductivity was interpreted as a decrease in ${ }^{\tau} \mathrm{PCD}$ caused by sweepout. The distance from the end contacts $L_{c}$ at which sweep-out first became noticeable was recorded in.terms of the number of drift lengths, that is, in terms of the ratio $\mathrm{L}_{c} / \mathrm{d}$. The specimens profiled and the $\mathrm{L}_{c} / \mathrm{d}$ ratios obtained are shown in table 9 .

In interpreting the data in table 9, two considerations need to be kept in mind. In the first place the diffusion length was not subtracted from the drift lengths. This may account for some of the variation between specimens. In the second place, in a PCD measurement a broader band of illumination is used than was used in the PC scans. Illuminating a larger portion of the specimen tends to keep the decay time at its average value even though a few excess carriers at the edge of the illumination might be swept out. It is therefore not necessary to interpret the data of table 9 too conservatively. Based on these considerations it appears that if the illumination is restricted from the regions within four drift lengths of each end contact sweep-out effects would not be expected to interfere with the measurement. Under these conditions, $\mathrm{L}_{c}$ would be chosen to be greater than or equal to four times $d$ as given by eq (11).

Assuming that the experimental conditions can be selected to prevent sweep-out, it is then necessary to verify that diffusion (as opposed to drift) to the end contacts is not present. The present standards [3, 4] recommend that specimens for PCD measurements be cut to one of three preferred sizes. The largest of these sizes, which for a given $\tau_{B}$ would have the largest $\tau_{\mathrm{PCD}}$ and consequently the largest $\mathrm{L}_{\mathrm{D}}$, is 1.0 by 1.0 by $2.5 \mathrm{~cm}$. For the case in which the center half of such a specimen is i1luminated such that regions within $0.625 \mathrm{~cm}$ of each end contact are masked, it can be shown that $L_{c}$ is equal to approximately 3.5 diffusion lengths when ${ }^{\tau_{B}}=3 \tau_{P C D} \cdot$ When ${ }^{\tau_{B}}>3 \tau_{P C D} L_{C}$ will be less than 3.5 in terms of diffusion lengths, but under these conditions a ${ }^{\top} \mathrm{PCD}$ measurement is considered inadvisable for other reasons (see sec. 4). Because the excess carrier density is reduced by 97 percent in 3.5 diffusion lengths, diffusion to the end contacts can be made insignificant by illuminating only the center half of the specimen in the specimen geometries preferred in the standards. In as-grown crystals it would also be possible to render negligible diffusion to the end contacts in specimens sufficiently long.

If it is valid to assume that excess carriers do not diffuse to the end contacts and that sweep-out is the limiting factor in determing the maximum allowable specimen current, then the maximum specimen current can 
Table 9 - Number of Drift Lengths from

Each End Contact at Which Sweep-out

First Appeared for a Group of Specimens.

\begin{tabular}{lcc} 
Specimen & \multicolumn{2}{c}{$\begin{array}{c}\text { Distance from End Contact in } \\
\text { Drift Lengths at Which Sweep- } \\
\text { out Was First observed }\end{array}$} \\
& $\begin{array}{r}\text { Left End } \\
\text { Right End }\end{array}$ \\
R818A & 4.3 & 4.0 \\
SS14 & 2.6 & 3.7 \\
SS11 & 4.4 & 3.0 \\
$678 c / 1$ & 4.6 & 2.9 \\
SS5 & --- & 3.8 \\
SS8 & -- & 4.8
\end{tabular}


be derived from eq (11) for the case $L_{c}=4 d$ :

$$
i_{s}=\frac{T W L_{c}}{4 \rho \mu \tau \text { PCD }} \text {, }
$$

where $\rho$ is the specimen resistivity. If the center half of the specimen is illuminated such that $\mathrm{L}_{C}=\mathrm{L} / 4$, then eq (13) can be replaced by:

$$
i_{S}=\frac{T W L}{16 \rho \mu \tau \text { PCD }} \text {. }
$$

Whereas in the standards [3,4] the maximum acceptable electric field is determined by eq (10), a different approach is represented in eqs (13) and (14). This latter approach is also suggested by Benda, et al [38].

\subsection{Specimen Current and Ohmic Heating}

If the specimen current and resulting power dissipation are sufficiently large, the specimen temperature increases, resulting in a possible increase in $\tau_{P C D}$ (see sec. 5.5.). An experiment was set up to establish a criterion for identifying a maximum specimen current beyond which ohmic heating might occur. Twelve silicon specimens were selected, each of which was approximately the size of one of the three sizes preferred in the standards [3,4].* Each specimen was mounted in the PCD specimen holder and a sequence of specimen currents was applied to it. At each current level, 15 minutes was allowed for thermal stabilization. The temperature increase was determined from the resistivity as measured by a two-probe method [39] and the temperature coefficient of resistivity for each specimen [40]. The specimen current which caused a $0.25^{\circ} \mathrm{C}$ temperature increase was determined by interpolating between the selected currents. From this current, the power dissipated, the power dissipated per unit specimen surface area, and the power dissipated per unit specimen volume were all calculated. These power dissipations were calculated in two ways: (1) total power dissipated based on a measurement of the specimen resistance which included contact resistance, and (2) bulk power dissipated based on bulk resistance (calculated from the measured resistivity and the specimen geometry) which did not include contact resistance. The resulting six quantities are tabulated in table 10 for each specimen. From these data it can be shown that (1) the power dissipated (total or bulk) at which the specimen temperature increased by $0.25^{\circ} \mathrm{C}$ for the twelve specimens had a lesser variability in terms of percent standard deviation than did either the power dissipated per unit surface area or power dissipated per unit volume, (2) the total power dissipated at which the specimen temperature increased by $0.25^{\circ} \mathrm{C}$ for the twelve specimens had a lesser variability in terms of percent standard deviation and overall range than did the bulk power dissipated, and (3) the total power

\footnotetext{
* In place of the $1.5 \mathrm{~cm}$ length suggested by the standards for the size A geometry, the specimens were all approximately $2.5 \mathrm{~cm}$ in length.
} 


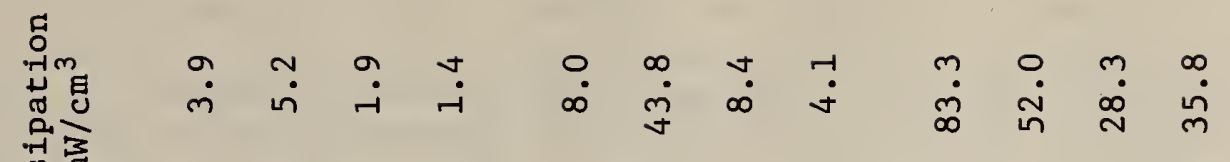

苞

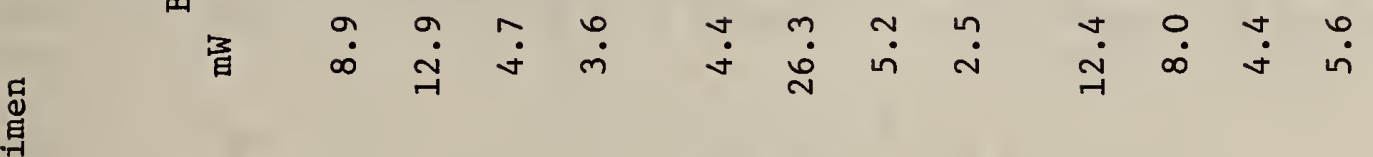

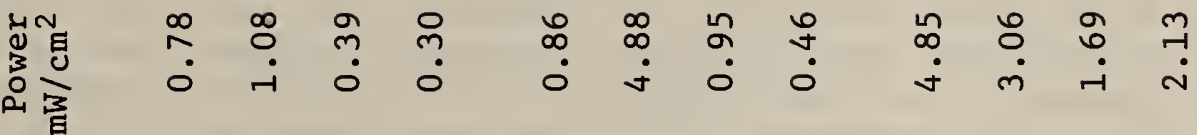
$x$ 学

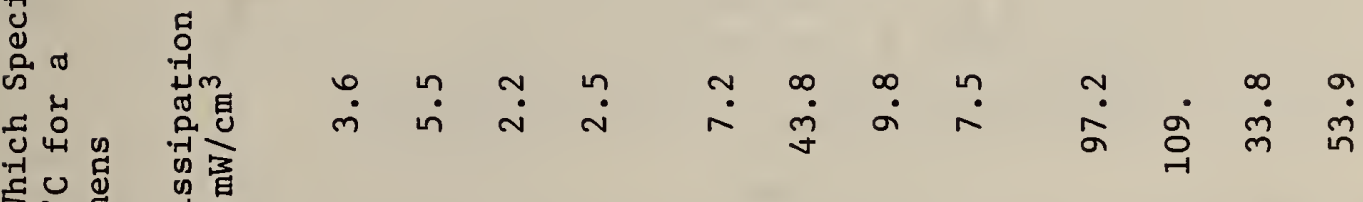

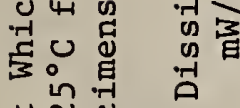
น

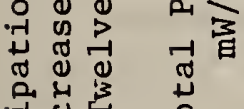

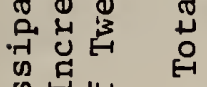
की 舁世 क 宫嵒 녈을

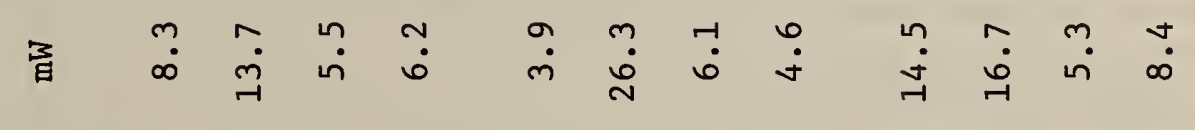
ऽ이

म

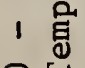

욱닫

$\stackrel{0}{2}$

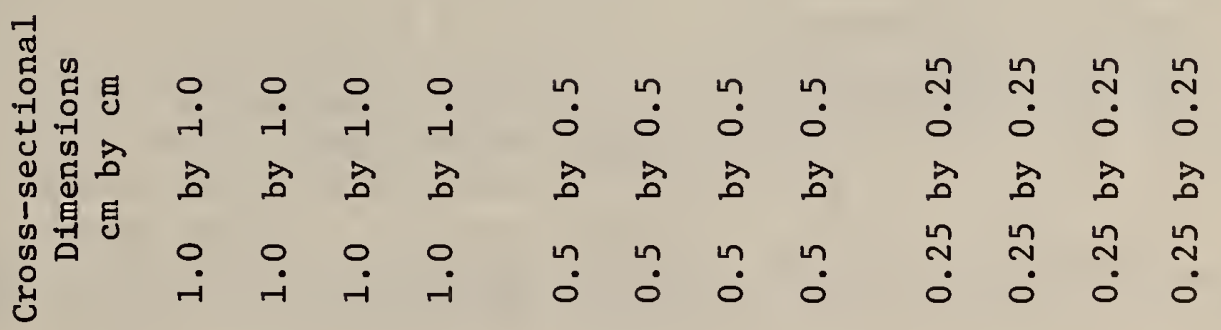

品

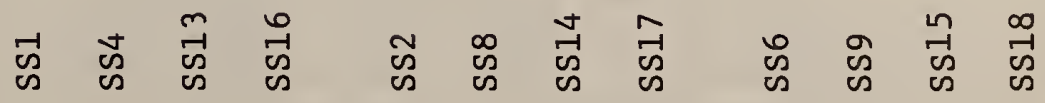


dissipated at which the specimen temperature increased by $0.25^{\circ} \mathrm{C}$ did not appear to depend to an appreciable extent on the specimen geometry.

Since the total power dissipated is the least variable of the six quantities calculated, it appears to be the most suitable parameter upon which to base a specification for the maximum specimen current with respect to ohmic heating. However, calculations are more easily based on the bulk power dissipated since $\rho$ has already been measured. The total power dissipated can then be limited by specifying that contact resistance not exceed a fixed percentage of the bulk specimen resistance. For example if it were determined that total power dissipation in preferred size silicon specimens should not exceed $5 \mathrm{~mW}$ and that $R_{c} \leq 0.25 \mathrm{R}$, then the maximum bulk power dissipated would be $4 \mathrm{~mW}$ and the maximum specimen current would be given by:

$$
i_{S}=\left[\frac{0.004 \mathrm{TW}}{\rho \mathrm{L}}\right]^{1 / 2},
$$

where eq (15) is of the form current $=\sqrt{\text { power/resistance. }}$

In practice it is usually necessary to calculate a maximum specimen current for both the power dissipation and the sweep-out limitations. The lesser of these two currents should then be used in the PCD measurement. When measuring specimens larger than the largest of the three preferred geometries the total power dissipation limit may be different from the limit established for the geometries preferred in the standards. In such instances it must also be verified that diffusion of excess carriers to the end contacts is not significant (see sec.6.3.).

\subsection{Specimen End Contacts}

Ohmic contact must be made to the specimen. This is usually a twostep process involving first the formation of a soldered, alloyed or evaporated metal-to-semiconductor contact at each end of the specimen and second the electrical connection of a wire to each contact. A variety of procedures has been developed for both silicon and germanium [3, 4, 9 , $19,30,41,42]$. In the present experiments, ohmic contacts were formed by lapping the specimen ends with $12 \mu \mathrm{m}$ alumina and then evaporating a 300-nm thick layer of gold or aluminum onto the specimen ends. Electrical connection was then made either by thin copper sheets or by goldplated copper screens with foam rubber backing pressed against the contacts.

Regardless of the care which is taken in making ohmic contact to the specimen, contact resistance is often present which is a significant fraction of the bulk specimen resistance. The bulk specimen resistance or resistivity, required in eqs (6), (13), (14) and (15) can be measured by the two-probe method [39]. From the results of this measurement, the contact resistance can be determined and the quality of the end contacts evaluated. 


\section{TRAPPING}

Recombination in silicon and germanium takes place primarily through energy states or recombination centers within the forbidden gap caused by lattice defects or impurity atoms. For instance, a conduction band electron might fall into a recombination center. If a valence band hole then falls into the same center, a hole-electron pair has been annihilated and recombination has occured. Sometimes, however, centers exist for which a captured electron is more likely to be emitted to the conduction band than to recombine with a hole. The electron is said to be trapped and the center is called a trap. If recombination does not occur, the electron remains trapped until it is excited to the conduction band. Such excitation may require much more time than recombination through ordinary recombination centers. The trapping of holes is analogous to that of electrons. If minority carriers are trapped, photoconductive decay is governed by the release of minority carriers from the traps and the result is an erroneously long $\tau_{P C D}$ measurement. Experimental studies of the phenomenon of trapping [43-46] and mathematical models to describe the behavior of excess carriers in the presence of trapping [31, 44] are reported in the literature.

Trapping is sometimes present in silicon at room temperature and in germanium at lower temperatures. It is most easily identified by a PCD curve which has an initial short-time-constant portion followed by a long-time-constant tail. The tail can usually be eliminated by flooding the specimen with a steady background light $[3,4,46,47]$. Such a procedure produces a decay curve which is more nearly exponential. However, the background light also acts to increase the specimen temperature and create a steady-state carrier density larger than the equilibrium carrier density, so that the measurement is no longer a low level measurement. Unless specifications are made regarding the background light, PCD measurements made under these conditions may have poor reproducibility.

In some applications, the PCD method is used to detect trapping. Only relatively large trap concentrations can be detected as tailing, however. It is possible that trapping might also be detected by noting a decrease in ${ }^{\tau}$ PCD with increasing temperature [9].

In the presence of trapping the hole and electron lifetimes differ. The hole and electron lifetimes can also differ when the density of recombination centers is not small in comparison with the majority carrier density. Transient recombination in the presence of an arbitrary density of recombination centers is very difficult to analyze. Blakemore [21] gives approximate analytical expressions for the initial and final portions of the decay and presents computer drawn decay curves for holes and electrons under a variety of special conditions. Because the PCD method measures changes in conductivity, it is unable to separate hole and electron lifetimes where they differ and yields instead a weighted average of the two. 
The present standards [3, 4] specify that the measurement should not be made when the trapping tail constitutes more than five percent of the total amplitude of the curve. The surface photovoltage (SPV) method [48] and the photomagnetoelectric effect method [49] are more suitable for measuring carrier lifetime in the presence of trapping.

\section{SUMMARY}

An investigation of the photoconductive decay method for measuring carrier lifetime has been completed. Analytical and experimental studies were conducted to determine suitable conditions under which the measurement could be made. Suitable conditions are those such that (1) the assumptions underlying the equations by which the measured decay time ${ }^{\tau} \mathrm{PCD}$ and the bulk decay time $\tau_{B}$ are related are valid, (2) the predicted percent standard deviation is acceptable, (3) the measurement is made under low-level conditions, and (4) the experimental apparatus is not overly complex. In order to define the suitable measurement conditions, the following parameters were studied: (1) the excess carrier density, (2) the type of light source, (3) specimen inhomogeneities, (4) filter thickness, (5) specimen temperature, (6) chopped light turn-off time, (7) resistance in series with the specimen, (8) specimen current and its relation to sweep-out, illumination pattern and ohmic heating, (9) end contact quality, and (10) trapping in the specimen.

The dependence of $\tau_{P C D}$ on excess carrier density and therefore on PCD signal level was verified in several specimens. Because correction factors by which ${ }^{\top} \mathrm{PCD}$ measurement made at an arbitrary excess carrier density could be corrected to a reference excess carrier density are not generally known, it is necessary to measure $\tau_{P C D}$ at a selected value of excess carrier density or signal level. An experiment was performed to determine a minimum acceptable signal level in terms of measurement reproducibility. It was found, however, that the behavior of the measurement reproducibility as a function of signal level showed considerable variation among the specimens tested. A generally applicable signal level was therefore not found. An expression was developed, however, for signal level in terms of other specimen parameters.

Measurements of ${ }^{\tau} \mathrm{PCD}$ using chopped and pulsed light sources were compared. The chopped light source was found to give a $\tau_{P C D}$ value which for the five specimens measured averaged about 10 percent longer than the value measured with the pulsed light source. The chopped light measurements also had a smaller sample percent standard deviation than did the pulsed light measurements.

The presence of inhomogeneities was verified in two crystals.

The photoductive decay time of a group of specimens was measured using filters of different thicknesses. The effect of the filter was greater with pulsed light than with chopped light. With either light source, increasing the filter thickness beyond $1 \mathrm{~mm}$ produced no significant change in ${ }^{\tau} \mathrm{PCD}$ in most specimens. Anomalous dependence of ${ }^{\tau} \mathrm{PCD}$ on 
filter thickness was shown to be caused by an inhomogeneity in one specimen.

The dependence of ${ }^{\tau} \mathrm{PCD}$ on temperature around room temperature was measured on four specimens. Because correction factors by which $\tau_{P C D}$ values measured at an arbitrary temperature could be corrected to a reference temperature are not generally known, only $\tau_{\mathrm{PCD}}$ measurements made at the same temperature may be compared.

The effect of chopped light turnoff time was observed on five specimens. Although ideally, linear light turnoff should not affect the ${ }^{2} P C D$ measurement unless $t_{\text {off }} \geqslant 4 \tau_{\mathrm{PCD}}$, due to rounding of the initial and final portions of the turnoff characteristic, the measurement was in fact affected for $t_{\text {off }} \approx 2 \tau_{P C D}$.

It was demonstrated that the series resistance $R_{S}$ need not be many times larger than the specimen bulk resistance $R$. The ${ }^{2} P C D$ value and its reproducibility are not appreciably affected provided that $R_{S} \geq R$. It is necessary, however, to consider the effect of the reduced PCD signal level which results when $R_{S}$ is not large compared to $R$.

The selection of suitable specimen currents was shown to be governed by sweep-out, carrier diffusion to the end contacts, and ohmic heating. The sweep-out limitation on the specimen current was considered in terms of the drift length $d$. The distance from the illumination boundary to the end contact $\mathrm{L}_{c}$ at which sweep-out was first observed was measured for several specimens by a steady-state photoconductivity technique and was expressed in terms of $\mathrm{L}_{c} / d$. It was determined by analysis that carrier diffusion to the end contacts does not influence the measurement when specimens having one of the three geometries preferred in the standards are illuminated in their center half.

An experiment was performed on twelve silicon specimens to determine a suitable limitation on the specimen current with respect to ohmic heating. The total power dissipated was the parameter which was least variable and therefore it appears to form the most suitable basis for a specification on the specimen current with regard to ohmic heating.

Specimen end contacts need to be sufficiently ohmic that excessive contact resistance does not interfere with the measurement. Many of the problems associated with excessive contact resistance can be avoided by making a two-probe resistivity measurement on the specimen, calculating the actual contact resistance, and correcting for it in the seperate equations. Where appropriate in this report, contact resistance was either explicitly accounted for (such as by defining $\mathrm{R}$ as bulk resistance to be determined by a two-probe measurement) or discussed in the text.

The PCD method is not applicable in the presence of trapping. Tailing which results from trapping can be reduced by applying steady background light to the specimen. This is done at the expense of increasing the excess carrier density, however. Other methods are suggested for measuring lifetime in the presence of trapping. 


\section{REFERENCES}

[1] Bullis, W. M., Measurement of Carrier Lifetime in Semiconductors An Annotated Bibliography Covering the Period 1949-1967, NBS Tech. Note 465, June, 1968.

[2] Mattis, R. L., Phillips, W. E., and Bullis, W. M., Measurement and Interpretation of Carrier Lifetime in Silicon and Germanium, May, 1968; AFML-TR-68-81. Available from the National Technical Information Service, Springfield, Virginia 22151, Accession No. AD 671552.

[3] IRE Standards on Solid-State Devices: Measurement of MinorityCarrier Lifetime in Germanium and Silicon by the Method of Photoconductive Decay (IEEE Standard 225), Proc. IRE 49, 1293-1299 (1961).

[4] Standard Method for Measuring Minority-Carrier Lifetime in Bulk Germanium and Silicon, ASTM Designation F28-66, Annual Book of ASTM Standards, Part 8 (American Society for Testing and Materials, Philadelphia, 1971).

[5] Use of the Terms Precision and Accuracy as Applied to Measurement of a Property of a Material, ASTM Designation E177-71, Annual Book of ASTM Standards, Part 30 (American Society for Testing and Materials, Philadelphia, 1971).

[6] IRE Standards on Solid-State Devices: Definition of Semiconductor Terms, 1960 (IEEE Standard 216), Proc. IRE 48, 1772-1775 (1960).

[7] Ryvkin, S. M., Photoelectric Effects in Semiconductors, pp. 237-245 (Consultants Bureau, New York, 1964).

[8] Stevenson, D. T., and Keyes, R. J., Measurement of Carrier Lifetimes in Germanium and Silicon, J. Appl. Phys. 26, 190-195 (1955).

[9] Watters, R. L., and Ludwig, G. W., Measurement of Minority Carrier Lifetime in Silicon, J. App Z. Phys. 27, 489-496 (1956).

[10] Dale, E. B., Beck, R., Peet, C. S., and Beer, A. C., Scientific Report No. 2, Measurements of Bulk Lifetime in Silicon, May 15, 1957, Contract No. AF19(604)-1852, (Available from the National Technical Information Service, Springfield, Virginia 22151, Accession No. $\mathrm{AD} 117072$.

[11] Gutberlet-Vieweg, F., Verbesserungen am Gleichstrom-PhotodecayVerfahren zur Ermittlung des Minoritätsträger-Lebensdauer in Silicium-Einkristallen, Archiv. Techn. Messen 366, 151-154 (1966).

[12] Shockley, W., Electrons and Holes in Semiconductors (Princeton, New Jersey: D. Van Nostrand Company, Inc., 1950), pp. 318-325. 
[13] van Roosbroeck, W., The Transport of Added Current Carriers in a Homogeneous Semiconductor, Phys. Rev. 91, 282-289 (1953).

[14] Blakemore, J. S., and Nomura, K. C., Influence of Transverse Modes on Photoconductive Decay in Filaments, J. Appl. Phys. 31, 753-761 (1960).

[15] Shockley, W., and Read, W. T., Jr., Statistics of the Recombinations of Holes and Electrons, Phys. Rev. 87, 835-842 (1952).

[16] Hall, R. N., Electron-Hole Recombination in Germanium, Phys. Rev. 87, 387 (1952).

[17] Blakemore, J. S., Lifetime in p-Type Silicon, Phys. Rev. 110, 1301-1308 (1958).

[18] Okada, J., Recombination Centers in Germanium, J. Phys. Soc. Japan 13, 793-800 (1958).

[19] Ivanov, V. G., Recombination in High-Resistivity Silicon, Soviet Phys.-Solid State 8 , 1306-1307 (1966).

[20] Okada, J., Effect of External Illumination on Carrier Lifetime in Semiconductors, J. Phys. Soc. Japan 14, 1550-1557 (1959).

[21] Blakemore, J. S., Semiconductor Statistics (New York: Pergamon Press, 1962).

[22] Ridley, B. K., Measurement of Lifetime by the Photoconductive Decay Method, J. Electronics Control $\underline{5}, 549-558$ (1958).

[23] Buimistrov, V. M., Theory of the Photodiffusion Effect Caused by a Non-uniform Distribution of Recombination Centers, Soviet Phys.Solid State $\underline{5}, 351-356$ (1963).

[24] Kovtonyuk, N. F., Recombination-Gradient Photo-emf in Semiconductors, Soviet Phys.-Solid State 7, 1243-1244 (1965).

[25] Suleiman, G. I., Kovtonyuk, N. F., and Kokorev, D. T., Automatic Apparatus for Recording the Lifetime Distribution of Nonequilibrium Charge Carriers in Semiconductors, Instrum. Exper. Tech. $\underline{8}$, 203-205 (1965).

[26] Esposito, R. M., Loferski, J. J., and Flicker, H., Concerning the Possibility of Observing Lifetime-Gradient and Dember Photovoltages in Semiconductors, J. Appl. Phys. 38, 825-831 (1967).

[27] Shachar, G., The Generation of Lifetime-Gradient Photovoltages in Photoconductors, J. App Z. Phys. 38, 5412-5413 (1967). 
[28] Sim, A. C., A Note on the Use of Filters in Photo-conductive Decay Measurements, Proc. IEE, Paper 2885E, May 1959, vol. 106B, Suppl. 非15, 308-310.

[29] Susila, G., and Suryan, G., Temperature Dependence of Recombination and Trapping in Germanium, Indian J. Pure Appl. Phys. 2, 125-129 (1964).

[30] Sandiford, D. J., Temperature Dependence of Carrier Lifetime in Silicon, Proc. Phys. Soc. $71,1002-1006$ (1958).

[31] Streetman, B. G., Carrier Recombination and Trapping Effects in Transient Photoconductive Decay Measurements, J. Appl. Phys. 37, 3137-3144 (1966).

[32] Okada, J., Recombination of Excess Carriers in Semiconductors, $J$. Phys. Soc. Japan 12, 1338-1344 (1957).

[33] Leadon, R., and Naber, J. A., Recombination Lifetimes in HighPurity Silicon at Low Temperatures, J. Appl. Phys. 40, 2633-2638 (1969).

[34] Susila, G., A Method for the Determination of Short Lifetime of Carriers in a Photoconductor from the Transient Photoresponse, Indian J. Pure Appl. Phys. 2, 44-47 (1964).

[35] Penchina, C. M., and Levinstein, H., Measurement of Lifetimes in Photoconductors by Means of Optical Beating, Infrared Phys. 6, 173182 (1966).

[36] McCormick, J. R., and Henisch, H. K., Simple Equipment for Lifetime Measurements on Semiconductors, Amer. J. Phys. 33, 965-967 (1965).

[37] Ridley, B. K., The Effect of an Electric Field on the Decay of Excess Carriers in Semiconductors, Proc. Phys. Soc. 75, 157-161 (1960).

[38] Benda, H., Dannhäuser, F., and Spenke, E., Die praktische Bedeutung der sogenannten STEVENSON-KEYES-Bedingung bei der Lichtblitzmethode zur Bestimmung der Trägerlebensdauer, Siemens Forschungs- und Entwicklungs-berichte $\underline{3}$, to be published in August 1972 .

[39] Standard Methods of Test for Resistivity of Semiconductor Materials, ASTM Designation F43-71, Annual Book of ASTM Standards, Part 8, (American Society for Testing and Materials, Philadelphia, (1971).

[40] Bullis, W. M., Brewer, F. H., Kolstad, C. D., and Swartzendruber, L. J., Temperature Coefficient of Resistivity of Silicon and Germanium Near Room Temperature, Solid-State Electronics 11, 639-646 (1968). 
[41] Hogarth, C. A., A Study of Carrier Injecting Properties of Emitter Contacts and Light Spots at Normal and Moderately Elevated Temperatures, Proc. Phys. Soc. B66, 845-858 (1953).

[42] Ig1itsyn, N. I., Kontsevoi, Yu. A., and Kudin, V. D., Measurement of the Lifetime in Monocrystalline Silicon, Soviet Phys. Tech. Phys. 2, 1316-1321 (1957).

[43] Hogarth, C. A., On the Measurement of Minority Carrier Lifetimes in Silicon, Proc. Phys. Soc. B69, 791-795 (1956).

[44] Hornbeck, J. A., and Haynes, J. R., Trapping of Minority Carriers in Silicon I. p-Type Silicon, Phys. Rev. 97, 311-321 (1955).

[45] Haynes, J. R., and Hornbeck, J. A., Temporary Traps in Silicon and Germanium, Phys. Rev. 90, 152-153 (1953).

[46] Arthur, J. B., Bardsley, W., Gibson, A. F., and Hogarth, C. A., On the Measurement of Minority Carrier Lifetime in n-Type Silicon, Proc. Phys. Soc. B68, 121-129 (1955).

[47] Bemski, G., Recombination in Semiconductors, Proc. IRE 46, 990-1004 (1958).

[48] Choo, S. C., and Sanderson, A. C., Bulk Trapping Effect on Carrier Diffusion Length as Determined by the Surface Photovoltage Method: Theory, Solid-State Electronics 13, 609-617 (1970).

[49] Zitter, R. N., Role of Traps in the Photoelectromagnetic and Photoconductive Effects, Phys. Rev. 112, 852-855 (1958). 
In table 11 below the specimens referred to in the report are identified and their type and material, nominal resistivity, and nominal dimensions are given.

Table 11 - Specimen Characteristics

\begin{tabular}{|c|c|c|c|c|c|}
\hline Specimen & $\begin{array}{l}\text { Type and } \\
\text { Material }\end{array}$ & $\begin{array}{c}\text { Nominal } \\
\text { Resistivity, } \\
\Omega \cdot \mathrm{cm}\end{array}$ & $\begin{array}{l}\text { Nominal } \\
\text { Length }\end{array}$ & $\begin{array}{c}\text { Dimensi } \\
\text { Width }\end{array}$ & $\begin{array}{l}\text { ons, cm } \\
\text { Thickness }\end{array}$ \\
\hline DOFL & $n-\mathrm{Ge}$ & 30 & 2.5 & 1.0 & 1.0 \\
\hline NBS -13 & $p-\mathrm{Ge}$ & 18 & 2.15 & 0.75 & 0.75 \\
\hline SS1 & $p-\mathrm{Si}$ & 50 & 2.5 & 1.0 & 1.0 \\
\hline SS2 & $p-S i$ & 50 & 2.5 & 0.5 & 0.5 \\
\hline SS4 & $p-\mathrm{Si}$ & 270 & 2.5 & 1.0 & 1.0 \\
\hline SS 5 & $p-\mathrm{Si}$ & 270 & 2.5 & 0.5 & 0.5 \\
\hline SS 6 & $p-S i$ & 270 & 2.5 & 0.25 & 0.25 \\
\hline SS7 & $p-S i$ & 630 & 2.5 & 1.0 & 1.0 \\
\hline SS8 & $p-\mathrm{Si}$ & 630 & 2.5 & 0.5 & 0.5 \\
\hline SS9 & $p-S i$ & 630 & 2.5 & 0.25 & 0.25 \\
\hline SS10 & $n-\mathrm{Ge}$ & 8 & 2.5 & 1.0 & 1.0 \\
\hline SS11 & $n-\mathrm{Ge}$ & 8 & 2.5 & 0.5 & 0.5 \\
\hline SS12 & $n-\mathrm{Ge}$ & 8 & 2.5 & 0.25 & 0.25 \\
\hline SS13 & $n-\mathrm{Si}$ & 10 & 2.5 & 1.0 & 1.0 \\
\hline $\mathrm{SS} 14$ & $n-S i$ & 10 & 2.5 & 0.5 & 0.5 \\
\hline SS15 & $n-S i$ & 10 & 2.5 & 0.25 & 0.25 \\
\hline SS16 & $n-\mathrm{Si}$ & 0.9 & 2.5 & 1.0 & 1.0 \\
\hline SS17 & $n-\mathrm{Si}$ & 0.9 & 2.5 & 0.5 & 0.5 \\
\hline SS18 & $n-S i$ & 0.9 & 2.5 & 0.25 & 0.25 \\
\hline $452 \mathrm{D}$ & $n-\mathrm{Ge}$ & 32 & 2.5 & 1.0 & 1.0 \\
\hline $678 c / 1$ & $p-\mathrm{Ge}$ & 10 & 2.5 & 1.0 & 1.0 \\
\hline $777 \mathrm{E}$ & $p-G e$ & 33 & 2.5 & 0.5 & 0.5 \\
\hline $12-620-3$ & $n-\mathrm{Si}$ & 60 & 10.5 & diam. & $\simeq 2.5$ \\
\hline $13069 / 3$ & $p-\mathrm{Si}$ & 550 & 8.0 & diam. & $\simeq 2.04$ \\
\hline $14787 / 5$ & $p-S i$ & 650 & 7.8 & diam. & $\simeq 2.4$ \\
\hline $15705 / 5$ & $p-\mathrm{Si}$ & 1400 & 5.1 & diam. & $\simeq 1.95$ \\
\hline $15710 / 3 b$ & $p-S i$ & 4500 & 9.2 & diam. & $\simeq 1.94$ \\
\hline $16444 / 2$ & $p-\mathrm{Si}$ & 1550 & 5.0 & diam. & $\simeq 1.99$ \\
\hline $52792 A$ & $p-\mathrm{Si}$ & 165 & 3.5 & diam. & $\simeq 2.36$ \\
\hline R818 & $p-\mathrm{Si}$ & 40 & 2.5 & 0.4 & 0.4 \\
\hline
\end{tabular}


FORM NBS-114A $(1-71)$

\begin{tabular}{|c|c|c|}
\hline $\begin{array}{l}\text { U.S. DEPT. OF COMM. } \\
\text { BIBLIOGRAPHIC DATA } \\
\text { SHEET }\end{array}$ & $\begin{array}{l}\text { 1. PUBLICATION OR REPORT NO. } \\
\text { NBS-TN-736 }\end{array}$ & 3. Recipient's Accession No. \\
\hline \multirow{2}{*}{\multicolumn{2}{|c|}{$\begin{array}{l}\text { 4. TITLE AND SUBTITLE } \\
\text { Carrier Lifetime Measurement by the Photoconductive Decay } \\
\text { Method }\end{array}$}} & $\begin{array}{l}\text { 5. } \text { Publication Date } \\
\text { September } 1972\end{array}$ \\
\hline & & 6. Performing Organization Code \\
\hline \multicolumn{2}{|c|}{$\begin{array}{l}\text { 7. AUTHOR(S) } \\
\text { Richard L. Mattis and A. James Baroody, Jr. }\end{array}$} & 8. Performing Organization \\
\hline \multirow{2}{*}{\multicolumn{2}{|c|}{$\begin{array}{l}\text { 9. PERF ORMING ORGANIZATION NAME AND ADDRESS } \\
\qquad \begin{array}{l}\text { NATIONAL BUREAU OF STANDARDS } \\
\text { DEPARTMENT OF COMMERCE } \\
\text { WASHINGTON, D.C. } 20234\end{array}\end{array}$}} & $\begin{array}{l}\text { 10. Project/Task/Work Unit No. } \\
4259522 \quad 4251126\end{array}$ \\
\hline & & $\begin{array}{l}\text { 11. Contract/Grant No. } \\
\text { DNA PO } 808-70\end{array}$ \\
\hline \multirow{2}{*}{\multicolumn{2}{|c|}{$\begin{array}{ll}\text { 12. Sponsoring Organization Name and Address } & \\
\text { National Bureau of Standards } & \text { Defense Nuclear Agency } \\
\text { Washington, D. C. } 20234 & \text { Washington, D. C. } 20305\end{array}$}} & $\begin{array}{l}\text { 13. Type of Report \& Period } \\
\text { Covered } \\
\text { Inter im }\end{array}$ \\
\hline & & 14. Sponsoring Agency Code \\
\hline
\end{tabular}

15. SUPPLEMENTARY NOTES

16. ABSTRACT (A 200-word or less factual summary of most significant information. If document includes a significant bibliography or literature survey, mention it here.)

The photoconductive decay (PCD) method of carrier lifetime measurement is discussed with emphasis on experimental and analytical work done at NBS. The relationship between photoconductive decay time $\tau_{P C D}$, bulk decay time $\tau_{B}$, and lifetime is described briefly and the PCD method is summarized. The determination of $\tau_{B}$ from $\tau_{P C D}$ and the influence of higher modes of recombination are discussed.

Experimental data, supported by theoretical considerations, are presented to demonstrate the dependence of $\tau_{P C D}$ on excess carrier density, the type of 1ight source, specimen homogeneity, filter thickness, and temperature. The dependences of $\tau$ PCD on excess carrier density and temperature are consequences of the statistics of the recombination process. Measurements made with chopped light excitation are shown to be less in error due to higher modes of recombination than are measurements made with pulsed 11ght excitation. The presence of inhomogeneities is verified in two crystals. Use of a filter is also shown to reduce the influence of higher modes. An unexpected reduction in $\tau P C D$ with increasing filter thickness is shown to be caused by an inhomogeneity.

Other experimental conditions are discussed as they affect the measurement of $\tau_{P C D}$. It is shown that the light turnoff must be sufficiently fast and the series resistance sufficiently large that they do not interfere with the measurement. Equations are developed whereby the specimen current and illumination pattern can be chosen such that carrier sweep-out at the ends of the specimen and ohmic heating are avoided. The end contacts must be sufficiently ohmic that excessive contact resistance does not interfere with the measurement.

17. KEY WORDS (Alphabetical order, separated by semicolons)

Carrier 1ifetime; germanium; photoconductive decay; silicon.

\begin{tabular}{|c|c|c|}
\hline $\begin{array}{l}\text { 18. AVAILABILITY STATEMENT } \\
\square \text { UNLIMITED. }\end{array}$ & $\begin{array}{l}\text { 19. SECURITY CLASS } \\
\text { (THIS REPORT) } \\
\text { UNCL ASSIF IED }\end{array}$ & $\begin{array}{l}\text { 21. NO. OF PAGES } \\
52\end{array}$ \\
\hline $\begin{array}{l}\square \text { FOR OFFIClAL. DISTRIBUTION. DO NOT RELEASE } \\
\text { TO NTIS. }\end{array}$ & $\begin{array}{l}\text { 20. SECURITY CLASS } \\
\text { (THIS PAGE) } \\
\text { UNCL ASSIFIED }\end{array}$ & $\begin{array}{r}\text { 22. Price } \\
50 \phi\end{array}$ \\
\hline
\end{tabular}


Trapping is defined and the means for identifying it are discussed briefly. The PCD method is inappropriate for determining minority carrier lifetime when trapping is present or under other circumstances when the hole and electron lifetimes are unequal. 
PERIODICALS

JOURNAL OF RESEARCH reports National Bureau of Standards research and development in physics, mathematics, and chemistry. Comprehensive scientific papers give complete details of the work, including laboratory data, experimental procedures, and theoretical and mathematical analyses. Illustrated with photographs, drawings, and charts. Includes listings of other NBS papers as issued.

Published in two sections, available separately:

\section{- Physics and Chemistry}

Papers of interest primarily to scientists working in these fields. This section covers a broad range of physical and chemical research, with major emphasis on standards of physical measurement, fundamental constants, and properties of matter. Issued six times a year. Annual subscription: Domestic, $\$ 9.50 ; \$ 2.25$ additional for foreign mailing.

\section{- Mathematical Sciences}

Studies and compilations designed mainly for the mathematician and theoretical physicist. Topics in mathematical statistics, theory of experiment design, numerical analysis, theoretical physics and chemisry, logical design and programming of computers and computer systems. Short numerical tables. Issued quarterly. Annual subscription: Domestic, \$5.00; $\$ 1.25$ additional for foreign mailing.

\section{TECHNICAL NEWS BULLETIN}

The best single source of information concerning the 3ureau's measurement, research, developmental, coperative, and publication activities, this monthly jublication is designed for the industry-oriented ndividual whose daily work involves intimate contact with science and technology-for engineers, chemists, Shysicists, research managers, product-development nanagers, and company executives. Includes listing of Ill NBS papers as issued. Annual subscription: Donestic, $\$ 3.00 ; \$ 1.00$ additional for foreign mailing.

\section{Bibliographic Subscription Services}

The following current-awareness and literaturesurvey bibliographies are issued periodically by the Bureau: Cryogenic Data Center Current Awareness Service (weekly), Liquefied Natural Gas (quarterly), Superconducting Devices and Materials (quarterly), and Electromagnetic Metrology Current Awareness Service (monthly). Available only from NBS Boulder Laboratories. Ordering and cost information may be obtained from the Program Information Office, National Bureau of Standards, Boulder, Colorado 80302.

\section{NONPERIODICALS}

Applied Mathematics Series. Mathematical tables, manuals, and studies.

Building Science Series. Research results, test methods, and performance criteria of building materials, components, systems, and structures.

Handbooks. Recommended codes of engineering and industrial practice (including safety codes) developed in cooperation with interested industries, professional organizations, and regulatory bodies.

Special Publications. Proceedings of NBS conferences, bibliographies, annual reports, wall charts, pamphlets, etc.

Monographs. Major contributions to the technical literature on various subjects related to the Bureau's scientific and technical activities.

National Standard Reference Data Series. NSRDS provides quantitative data on the physical and chemical properties of materials, compiled from the world's literature and critically evaluated.

Product Standards. Provide requirements for sizes, types, quality, and methods for testing various industrial products. These standards are developed cooperatively with interested Government and industry groups and provide the basis for common understanding of product characteristics for both buyers and sellers. Their use is voluntary.

Technical Notes. This series consists of communications and reports (covering both other-agency and NBS-sponsored work) of limited or transitory interest.

Federal Information Processing Standards Publications. This series is the official publication within the Federal Government for information on standards adopted and promulgated under the Public Law 89-306, and Bureau of the Budget Circular A-86 entitled, Standardization of Data Elements and Codes in Data Systems.

Consumer Information Series. Practical information, based on NBS research and experience, covering areas of interest to the consumer. Easily understandable language and illustrations provide useful background knowledge for shopping in today's technological marketplace.

\section{CATALOGS OF NBS PUBLICATIONS}

NBS Special Publication 305, Publications of the NBS. 1966-1967. When ordering, include Catalog No. C13.10:305. Price $\$ 2.00: 50$ cents additional for foreign mailing.

NBS Special Publication 305, Supplement 1, Publications of the NBS, 1968-1969. When ordering, include Catalog No. C13.10:305/Suppl. 1. Price $\$ 4.50$ : $\$ 1.25$ additional for foreign mailing.

NBS Special Publication 305, Supplement 2, Publications of the NBS, 1970. When ordering, include Catalog No. C13.10:305/Suppl. 2. Price $\$ 3.25$ : 85 cents additional for foreign mailing. 
U.S. DEPARTMENT OF COMMERCE National Bureau of Standards

Washington, D.C. 20234

DFFICIAL BUSINESS

POSTAGE AND FEES PAID U.S. DEPARTMENT OF COMMEACE 215

Penalty for Private Use, $\$ 300$ 